University of Tennessee Health Science Center UTHSC Digital Commons

\title{
Coping Style and Blood Pressure in African Americans: The Jackson Heart Study
}

Sandra Henley Williams

University of Tennessee Health Science Center

Follow this and additional works at: https://dc.uthsc.edu/dissertations

Part of the Cardiovascular Diseases Commons, and the Mental and Social Health Commons

\section{Recommended Citation}

Williams, Sandra Henley, "Coping Style and Blood Pressure in African Americans: The Jackson Heart Study" (2010). Theses and Dissertations (ETD). Paper 305. http://dx.doi.org/10.21007/ etd.cghs.2010.0352.

This Dissertation is brought to you for free and open access by the College of Graduate Health Sciences at UTHSC Digital Commons. It has been accepted for inclusion in Theses and Dissertations (ETD) by an authorized administrator of UTHSC Digital Commons. For more information, please contact jwelch30@uthsc.edu. 


\title{
Coping Style and Blood Pressure in African Americans: The Jackson Heart Study
}

\begin{abstract}
Objective: To explore the relationship between coping style and blood pressure in African American men and women.

Participants: This descriptive correlational study consisted of 4354 adult men $(n=1557)$ and women $(n=$ 2797) enrolled in the Jackson Heart Study (JHS) who completed the Coping Strategies Short-Form (CSISF).

Results: Coping style mean score comparisons showed that JHS participants used engagement coping styles more than disengagement coping styles. The PFE subscale had the highest mean score $(15.10 \pm$ 2.63 ) with $75 \%$ of the PFE scores under 17.00 and $75 \%$ of EFE scores were below 15.00 . Comparatively, $75 \%$ of PFD scores fell below 13.00 and EFD fell below 10.00 respectively. Women had slightly higher scores than men on most subscales problem-focused engagement; problem-focused disengagement; emotion-focused engagement and, emotion-focused disengagement. Women had significantly higher coping scores than men on five of the six coping scales. Men had significantly higher scores than women on PFE. Further results revealed moderately strong correlations among coping styles (i.e. PFE, PFD, EFE, and EFD) such as significant positive correlations between SBP and PFD $(r=0.042, p<0.05)$ and significant negative correlations between DBP and EFE $(r=-0.041, p<0.05)$. Women tended toward higher disengagement scores while men tended to have higher PFE scores. PFD $(t=74.9180, p=0.0071)$ and EFD ( $t=1.9642, p=0.0495)$, both disengagement subscales, mediated the association between gender and systolic blood pressure. Two minor subscales and two major subscales were not significant mediators of systolic blood pressure. However, for diastolic blood pressure, only the minor subscale, EFE $(t=2.5707, p=0.0102)$ significantly mediated the relation of gender and diastolic blood pressure.
\end{abstract}

Discussion: Findings from the current study indicated that coping style does affect blood pressure and that there are significant gender-differences in coping style among African American men and women enrolled in the Jackson Heart Study.

\section{Document Type}

Dissertation

Degree Name

Doctor of Philosophy (PhD)

\section{Program}

Nursing

\section{Research Advisor}

Ann K. Cashion, Ph.D., R.N., FAAN

\section{Keywords}

African Americans, blood pressure, disengagement, emotion-focused coping, engagement, problemfocused coping

\section{Subject Categories}

Cardiovascular Diseases | Diseases | Medicine and Health Sciences | Mental and Social Health 


\title{
COPING STYLE AND BLOOD PRESSURE IN AFRICAN AMERICANS: THE JACKSON HEART STUDY
}

\author{
A Dissertation \\ Presented for \\ The Graduate Studies Council \\ The University of Tennessee \\ Health Science Center
}

In Partial Fulfillment

Of the Requirements for the Degree

Doctor of Philosophy

From The University of Tennessee

By

Sandra Henley Williams

December 2010 
Copyright (C) 2010 by Sandra Henley Williams. All rights reserved. 


\section{DEDICATION}

This dissertation is dedicated to my loving children Demarcus, Travis, Brandon, Kirsten and Alice; my father, Edwin Henley; my mother, Dethelder Lang; stepfather, Reaf Lang; my late stepmother, Feryne Henley; and my beloved husband, Billie Dunn, who lovingly and patiently nurtured, mentored and supported me through a myriad of hurdles during one of the most memorable chapters of my life. Your patience has been invaluable and is much appreciated.

"I can do all things through Christ who strengthens me" (Philippians 4:13, KJV). 


\section{ACKNOWLEDGEMENTS}

First, I would like to thank my Lord and savior Jesus Christ for the opportunity afforded to me to obtain a Ph.D. in nursing. I thank God for knowing that all things work together for the good of those who love him. I thank God for the mental, physical and emotional endurance rendered as I traveled to and from Memphis in pursuit of my Ph.D. in Nursing from the University of Tennessee Health Science Center.

Secondly, I would like to express my sincere gratitude to my advisor, Dr. Ann Cashion, whose continual mentoring and guidance helped to propel me towards completion of one of the most challenging milestones in my life.

In addition, I would like to extend heartfelt thanks to my dissertation committee: Dr. Patricia Cunningham, Dr. Carolyn Graff, Dr. Sharon Husch and Dr. Mona Wicks for exemplifying the image of research scholarship and professionalism and for all of the nurturing I received during the last four years.

Thirdly, I would like to thank the Jackson Heart Study (JHS) investigators for providing the data for my dissertation. I especially would like to thank JHS ad hoc dissertation committee members Dr. Frances Henderson and Dr. Daniel Sarpong for their countless hours of support. I would especially like to thank Dr. Henderson for her hospitality, nurturing, mentoring, and patience during this memorable event. I would also like to acknowledge Dr. Francine Nichols and Dr. Yvette Conley for all of the mentoring received while attending the NIH/NINR Summer Genetics Institute 2008. Other thanks are for the guidance extended to me by Dr. Bin Wang and Mrs. Ann McKenzie.

Lastly, I would like to thank my husband Billie, my children Demarcus, Travis, Brandon, Kirsten and Alice, my sisters Kathy, Pamela, Diann, and Loretta, my mother, Dethelder Lang and her husband Reaf Lang, my father, Edwin Henley, and his wife, Monique Henley for all of the love, support, and encouragement I received. I would also like to thank my cousin Sherrie and her husband, Napoleon, for providing for my daughter Alice when I traveled to Memphis. 


\begin{abstract}
Objective: To explore the relationship between coping style and blood pressure in African American men and women.

Participants: This descriptive correlational study consisted of 4354 adult men (n $=1557)$ and women $(\mathrm{n}=2797)$ enrolled in the Jackson Heart Study (JHS) who completed the Coping Strategies Short-Form (CSI-SF).

Results: Coping style mean score comparisons showed that JHS participants used engagement coping styles more than disengagement coping styles. The PFE subscale had the highest mean score $(15.10 \pm 2.63)$ with $75 \%$ of the PFE scores under 17.00 and $75 \%$ of EFE scores were below 15.00. Comparatively, 75\% of PFD scores fell below 13.00 and EFD fell below 10.00 respectively. Women had slightly higher scores than men on most subscales problem-focused engagement; problem-focused disengagement; emotionfocused engagement and, emotion-focused disengagement. Women had significantly higher coping scores than men on five of the six coping scales. Men had significantly higher scores than women on PFE. Further results revealed moderately strong correlations among coping styles (i.e. PFE, PFD, EFE, and EFD) such as significant positive correlations between SBP and PFD $(r=0.042, p<0.05)$ and significant negative correlations between DBP and EFE $(\mathrm{r}=-0.041, p<0.05)$. Women tended toward higher disengagement scores while men tended to have higher PFE scores. PFD $(t=74.9180, p$ $=0.0071)$ and EFD $(\mathrm{t}=1.9642, \mathrm{p}=0.0495)$, both disengagement subscales, mediated the association between gender and systolic blood pressure. Two minor subscales and two major subscales were not significant mediators of systolic blood pressure. However, for diastolic blood pressure, only the minor subscale, EFE $(t=2.5707, p=0.0102)$ significantly mediated the relation of gender and diastolic blood pressure.
\end{abstract}

Discussion: Findings from the current study indicated that coping style does affect blood pressure and that there are significant gender-differences in coping style among African American men and women enrolled in the Jackson Heart Study. 


\section{TABLE OF CONTENTS}

CHAPTER 1. INTRODUCTION..............................................................................

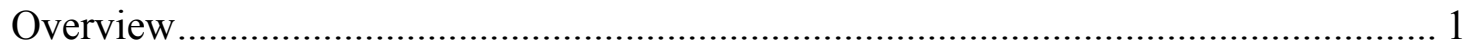

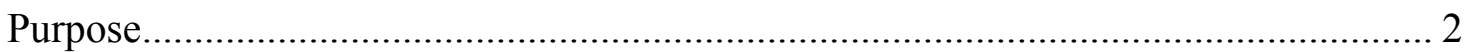

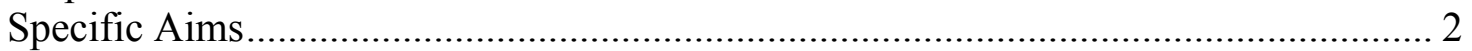

Aim One: To Characterize the Coping Style Used by African Americans in the

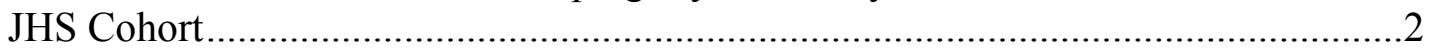

Aim Two: To Assess Gender Differences in Coping Styles of African Americans

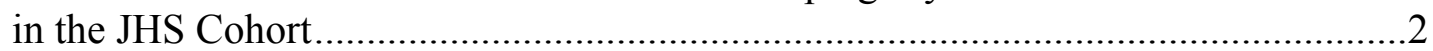

Aim Three: To Determine the Relationship between Coping Style and Blood

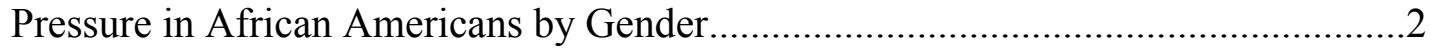

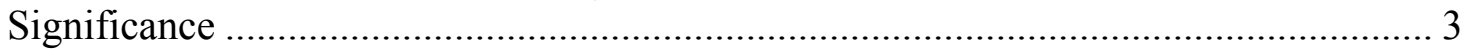

Theoretical Framework .................................................................................... 3

Conceptual Framework .................................................................................... 4

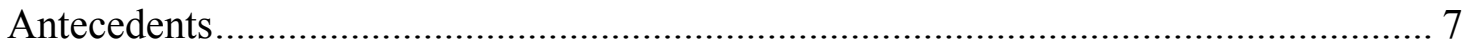

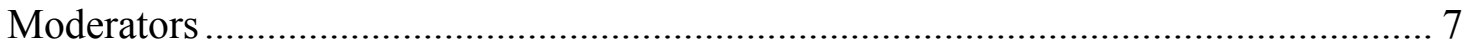

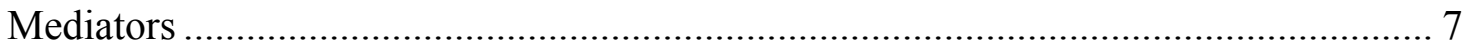

Definition of Key Terms .................................................................................... 8

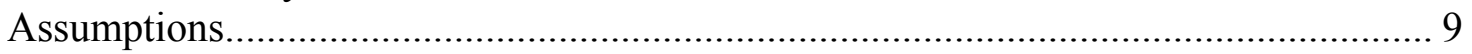

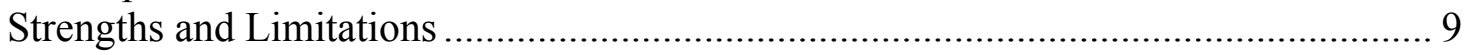

CHAPTER 2. REVIEW OF LITERATURE .......................................................

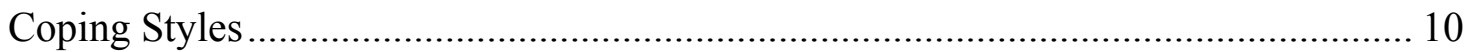

Engagement and Disengagement Coping ............................................................ 11

Problem-Focused Engagement Coping.............................................................. 12

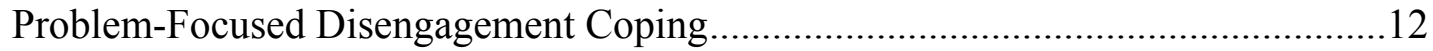

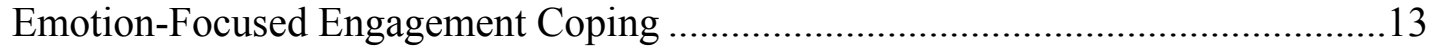

Emotion-Focused Disengagement Coping .......................................................... 13

Coping Styles and Gender .................................................................................. 13

Problem-Focused and Emotion-Focused Coping Styles and Gender .......................13

Emotion-Focused Disengagement Coping Styles and Men................................... 14

Emotion-Focused Disengagement Coping Styles and Women .............................. 14

Problem-Focused Engagement Coping Styles and Women ................................ 14

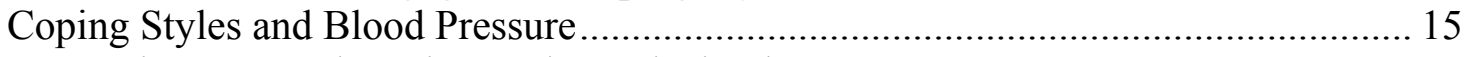

Emotion-Focused Coping Styles and Blood Pressure .........................................15

Emotion-Focused Engagement Coping Styles and Blood Pressure .........................15

Problem-Focused Coping Styles and Blood Pressure............................................16

Problem-Focused Engagement Coping Styles and Blood Pressure..........................16

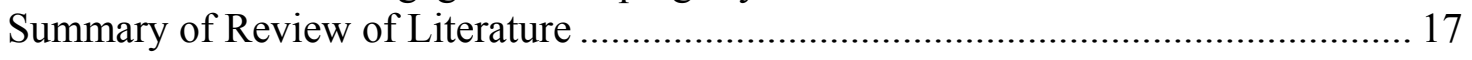

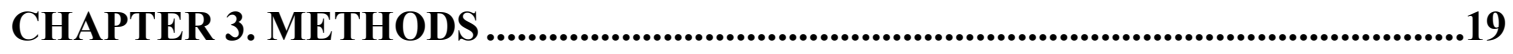

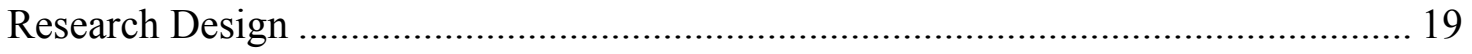

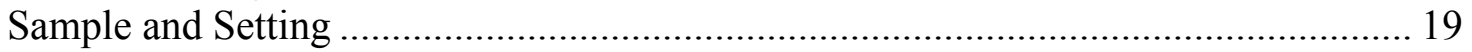


JHS Procedure for Data Collection on Coping Styles, Blood Pressure, Body Mass Index, Alcohol and Tobacco Use, Physical Activity, and Socioeconomic Status....... 19

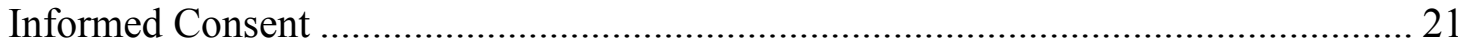

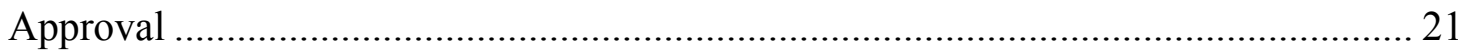

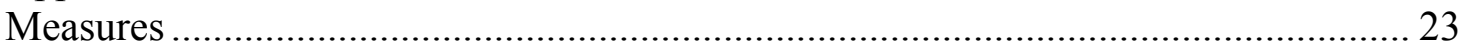

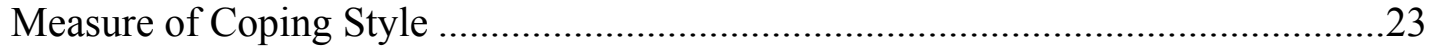

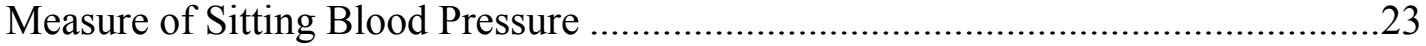

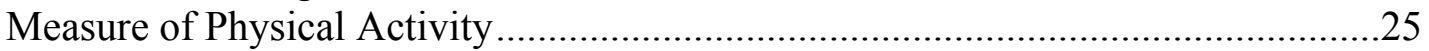

Measure of Alcohol Consumption ........................................................................25

Measure of Body Mass Index ............................................................................25

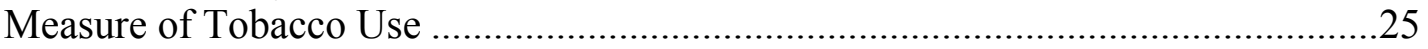

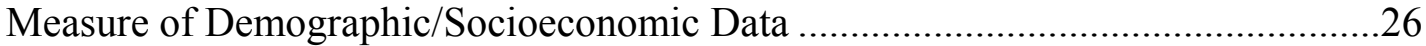

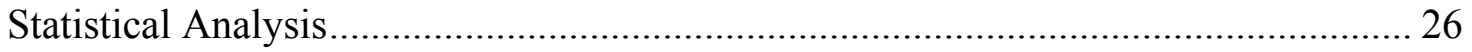

Mediation and Moderator Effects ...................................................................... 26

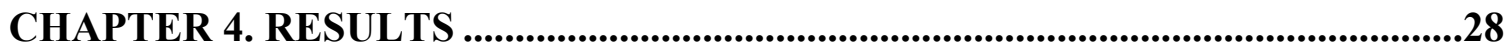

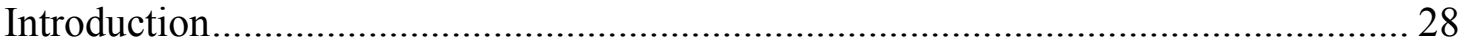

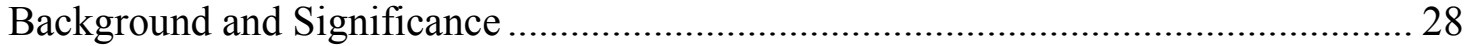

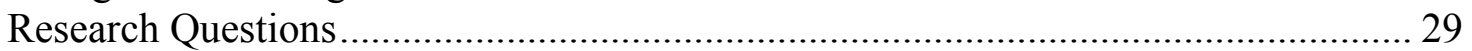

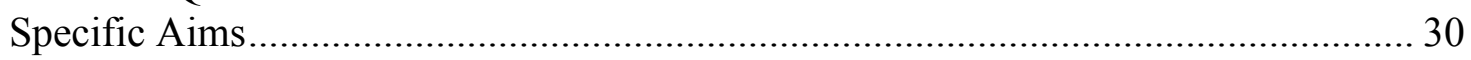

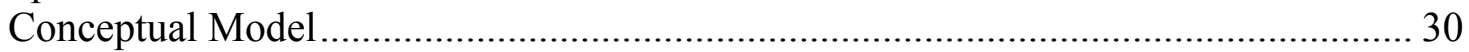

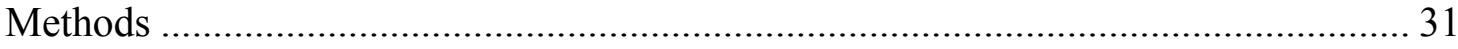

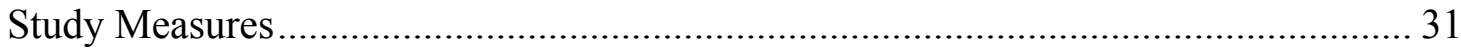

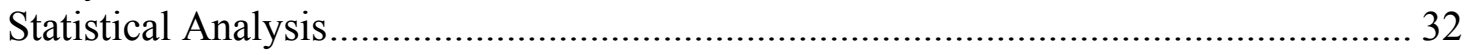

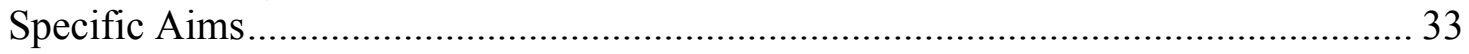

Aim One: To Characterize the Coping Style Used by African Americans ................33

Aim Two: To Assess Gender Differences in Coping Styles of African Americans..33

Aim Three: To Determine the Relationship between Coping Style and

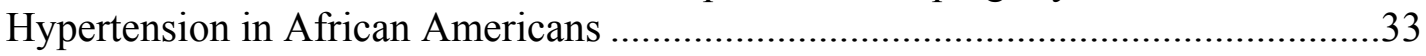

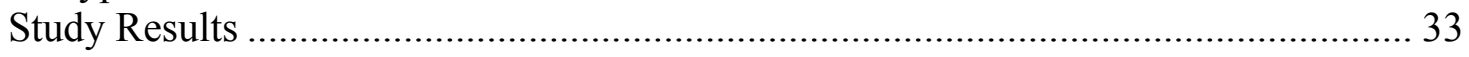

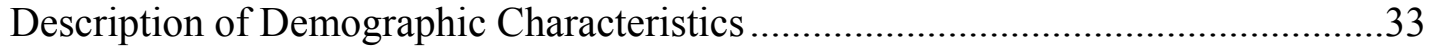

Description of Sample Cardiovascular Risk Characteristics ..................................35

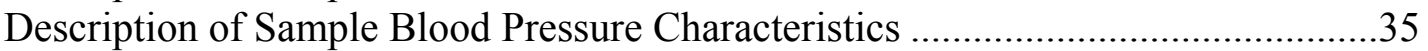

Aim One: Coping Styles Used by African Americans ............................................35

Aim Two: Gender Differences in Coping Styles Used by African Americans ..........39

Aim Three: Relationship between Coping Style and Blood Pressure in African

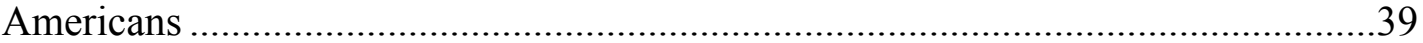

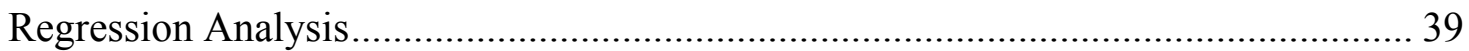

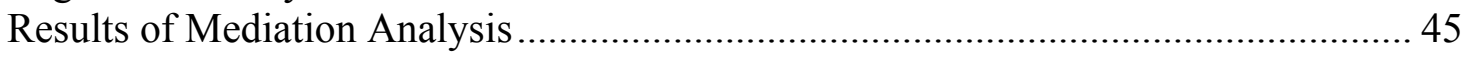

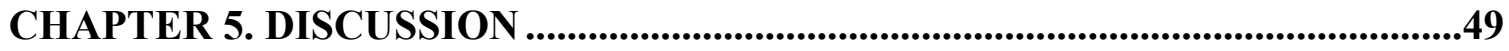

LIST OF REFERENCES..............................................................................................51

APPENDIX A. INSTITUTIONAL REVIEW BOARD APPROVAL LETTER.......57

APPENDIX B. JHS MANUSCRIPT PROPOSAL APPROVAL LETTER .............58

APPENDIX C. COPING STRATEGIES INVENTORY SHORT-FORM ...............60 
APPENDIX D. TOBACCO USE FORM ........................................................................63

APPENDIX E. ALCOHOL AND DRUG USE FORM .................................................68

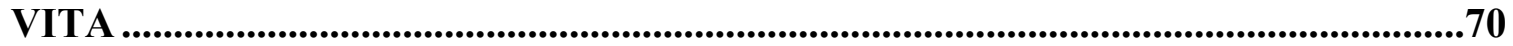




\section{LIST OF TABLES}

Table 3-1. Components of Jackson Heart Study Examination...................................20

Table 3-2. The Jackson Heart Study Home Induction Interview ..............................22

Table 3-3. The Coping Strategies Inventory Short-Form Subscales.........................24

Table 4-1. Description of Sample Demographic Characteristics ...............................34

Table 4-2. Description of Sample Cardiovascular Risk Characteristics ....................36

Table 4-3. Description of Sample Blood Pressure and Hypertension

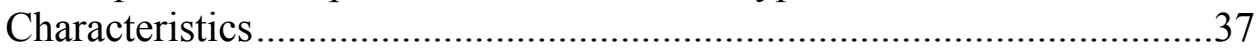

Table 4-4. Means and Standard Deviations of Coping Style Scores $(\mathrm{N}=4354) \ldots \ldots . .38$

Table 4-5. Coping Style Significance Results .................................................... 42

Table 4-6. Correlations between Coping and Blood Pressure..................................42

Table 4-7. Linear Regression of Systolic Blood Pressure on Gender and Coping

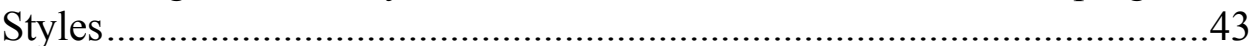

Table 4-8. Linear Regression of Diastolic Blood Pressure on Gender and Coping Styles

Table 4-9. $\quad$ Multiple Logistic Regression of Blood Pressure on Gender, Age, Income, Education, Smoking, Alcohol, Physical Activity, BMI, and Coping Styles

Table 4-10. Sobel Test of Mediation on the Relationship between Gender and Blood Pressure 


\section{LIST OF FIGURES}

Figure 1-1. The Transactional Model of Stress and Coping ........................................5

Figure 1-2. The Relationship between Gender Differences and Blood Pressure as Mediated by Cardiovascular Risk Factors ..............................................6

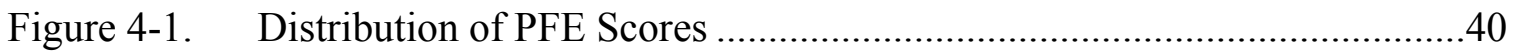

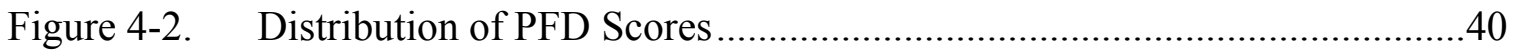

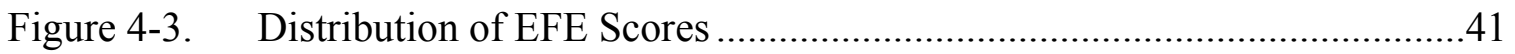

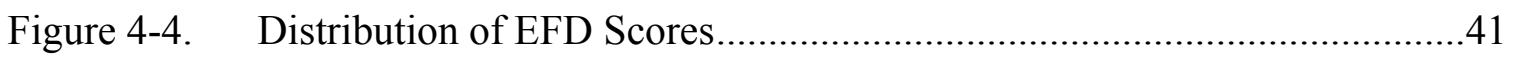

Figure 4-5. The Effects of Problem-Focused Disengagement and EmotionFocused Disengagement on Systolic Blood Pressure .............................48

Figure 4-6. The Effects of Emotion-Focused Engagement on Diastolic Blood Pressure 


\section{LIST OF ABBREVIATIONS}

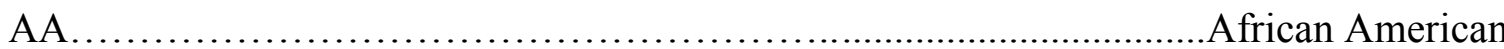

BMI Body Mass Index

$\mathrm{BP}$ Blood Pressure

CVD Cardiovascular Disease

DBP Diastolic Blood Pressure

$\mathrm{DC}$ Disengagement Coping EC Engagement Coping EFD Emotion-Focused Disengagement EFE Emotion-Focused Engagement

HTN. .Hypertension MSA Metropolitan Statistical Area

NTN Normotension

PFD Problem-Focused Disengagement PFE Problem-Focused Engagement

SBP. Systolic Blood Pressure

TD Total Disengagement TE Total Engagement 


\section{CHAPTER 1. INTRODUCTION}

\section{Overview}

African Americans (AAs) have the highest prevalence of hypertension [1-4] and the lowest blood pressure control rates of all ethnic groups in the United States [5]. Stressful life events within the African American community are well documented [6-11] and ineffective coping with these life events is thought to lead to increased blood pressure $[1-3,6,12-15]$. The style of coping used by African American men and women may be associated with health outcomes, such as high blood pressure [16, 17]. Even though many studies have explored coping in association with psychological stress and high blood pressure, few studies have examined the relationship between coping style, gender differences and behaviors that may predispose African Americans to increased cardiovascular risks. Because hypertension contributes to significant morbidity, mortality, and costs among African Americans and there is limited research examining the relationship between coping style and blood pressure in this population, a secondary data analysis was conducted to assess these variables in African Americans enrolled in the Jackson Heart Study (JHS).

The Jackson Heart Study is a single-site prospective epidemiologic examination of cardiovascular disease (CVD) of African Americans. The National Heart, Lung, and Blood Institute (NHLBI) and the National Center on Minority Health and Health Disparities (NCMHD) of the National Institute of Health (NIH) fund the JHS. There are three sponsoring institutions for the JHS: Jackson State University, the University of Mississippi Medical Center, and Tougaloo College. Although analysis of JHS data is ongoing, to date the association between coping style and blood pressure has not been examined in the study population.

Addison et al. conducted a psychometric evaluation of the Coping Strategies Inventory Short Form (CSI-SF) which was developed to measure coping styles in the JHS cohort [18]. They categorized coping into two major and four minor categories. The two major categories consist of engagement and disengagement. Engagement is assumed to limit the long-term negative consequences of stress and disengagement is believed to lead to poor long-term health consequences. Each major category is further categorized as either problem-focused, which emphasizes management of the stressful situation, or emotion-focused, which emphasizes the regulation of one's affective response coping style [19].

Variation in coping style may explain differences in blood pressure in African Americans [16]. The JHS data provide rich epidemiological resources to understand better the relationship between coping style and hypertension. Although the focus of the JHS is on cardiovascular disease risk factors, understanding the role of coping in the African American community may be significant in the prevention and treatment of hypertension in African Americans living in the south. 


\section{Purpose}

The purpose of this study was to explore the relationship between coping style and blood pressure in African American men and women. The JHS includes crosssectional data that can help elucidate the association between coping style and blood pressure in African Americans [20].

\section{Specific Aims}

The aims that guided this study were derived from the literature and are described next. Associated research questions follow each study aim.

Aim One: To Characterize the Coping Style Used by African Americans in the JHS Cohort

1. How is engagement coping characterized?

i. How is problem-focused engagement characterized?

ii. How is emotion-focused engagement characterized?

2. How is disengagement coping characterized?

i. How is problem-focused disengagement coping characterized?

ii. How is emotion-focused disengagement coping characterized?

Aim Two: To Assess Gender Differences in Coping Styles of African Americans in the JHS Cohort

1. Is engagement coping characterized by gender?

i. Is problem-focused engagement characterized by gender?

ii. Is emotion-focused engagement characterized by gender?

2. Is disengagement coping characterized by gender?

i. Is problem-focused disengagement characterized by gender?

ii. Is emotion-focused disengagement characterized by gender?

Aim Three: To Determine the Relationship between Coping Style and Blood Pressure in African Americans by Gender

1. What is the relationship between coping styles and systolic blood pressure, adjusted and unadjusted for age, tobacco use, physical activity and alcohol consumption in African American men and women?

2. What is the relationship between coping styles and diastolic blood pressure, adjusted and unadjusted for age, tobacco, physical activity and alcohol consumption in African American men and women? 
3. What is the relationship between coping style and normal blood pressure in African American men and women?

4. What is the relationship between coping style and high blood pressure in African American men and women?

\section{Significance}

The overall significance of this study is that information obtained will provide insight into the coping styles of African American men and women. Results will determine whether specific coping styles positively or negatively contribute to elevated blood pressure and hypertension in African Americans in the study sample. Identification of effective and ineffective coping styles as well as teaching effective coping could be important, low-cost approaches that could help manage blood pressure among demographically similar African Americans residing in the southeast region of the US.

Furthermore, findings from this study may contribute to the JHS's objective to identify environmental risk factors for the development and progression of cardiovascular disease in African American men and women. Increased knowledge of the ways in which African Americans cope could facilitate intervention development as well as future research focused on the reduction of blood pressure in African Americans [21].

\section{Theoretical Framework}

This study was based on the theory of psychological stress and coping developed by Lazarus and Folkman, who defined coping as the continual thoughts and behaviors used to manage specific stressors as appraised far too overwhelming to the person at that time [22]. According to Folkman and Lazarus, fundamental processes of coping include cognitive appraisal and coping, which are thought to mediate stressful personenvironment relationships [19, 23-25].

Cognitive appraisal refers to the thoughts concerning potential risks related to stressful events (primary appraisal) and the thoughts concerning what to do and how to handle stressful events are referred to as secondary appraisal [19]. According to the theory of psychological stress and coping, coping is the attempt to manage alterations in the person-environment relationship across time. Cognitive appraisal of a stressful situation can be influenced by coping style. For instance, the type of coping style used can indirectly or directly impact how the situation is appraised and what can be done about it [26]. The theory contends that individuals appraise stressful transactions as being threatening, challenging, or harmful. Coping processes are then implemented to either regulate emotions using emotion-focused coping styles or by managing problems using problem-focused coping styles, leading to either favorable or unfavorable outcomes [27]. 


\section{Conceptual Framework}

In designing the conceptual framework (CF) for this study the researcher utilized the theory of psychological stress and coping as a guide to facilitate understanding of the relationship between coping style and blood pressure [28]. The Transactional Model of Stress and Coping depicted in Figure 1-1 represents Lazarus and Folkman's theory of stress and coping and is used in this study to provide clarity for using the theory with JHS participants. In this theory, a stressful event such as a car accident can be seen as a threat. Depending on what's at stake (i.e., physical injury, damages to vehicle, etc.), the person will either approach the situation using a problem-focused engagement coping style or avoid the situation using an emotion-focused disengagement coping style. The outcome will be either favorable or unfavorable. A favorable outcome will occur as a result of some form of coping used versus unfavorable outcomes that result in distress and no coping [24].

Figure 1-2 depicts the CF for this study. The concepts of coping and event outcomes from the Transaction Model of stress and coping have been conceptualized as coping style (Figure 1-1). Blood pressure status in relation to coping styles, gender and cardiovascular disease risk factors is illustrated in Figure 1-2. Coping style consists of engagement, disengagement, problem-focused engagement, problem-focused disengagement, emotion-focused engagement and emotion-focused disengagement.

Stressful life events within the African-American community are well documented and ineffective coping with these life events is thought to contribute to increased blood pressure [29]. Other investigators have reported that coping styles have mediating effects. Figure 1-2 illustrates a) the path between the independent variable (gender) and the mediator variable (coping styles); b) the effect of the mediator (coping styles) on SBP, DBP, normotension, hypertension; c) the effect of gender on SBP and DBP; and d) the moderating effects of health behaviors on gender and SBP, DBP, normotension and hypertension. Normotension is defined as blood pressure $<140 / 90$ and no history of taking anti-hypertension medication) and hypertension is defined as SBP $\geq$ 140 , DBP $\geq 90$ or history of taking anti-hypertension medication (actual or self-reported) [5].

Coping can affect health outcomes negatively when individuals use unhealthy coping behaviors such as excessive alcohol consumption, cigarette smoking and physical inactivity. The disproportion of caloric intake in relation to physical activity leads to weight gain which can be measured by body weight in proportion to height, known as body mass index (BMI) [30]. These unhealthy behaviors, which when used to decrease stress, may be reflective of high level emotion-focused coping potentially leading to increased blood pressure [27].

The model implies that gender differences, stressors and coping styles may influence hypertension status in African American men and women enrolled in the JHS. Culturally, many African American families share dual responsibilities. African American women are usually responsible for taking care of things related to inside of the 


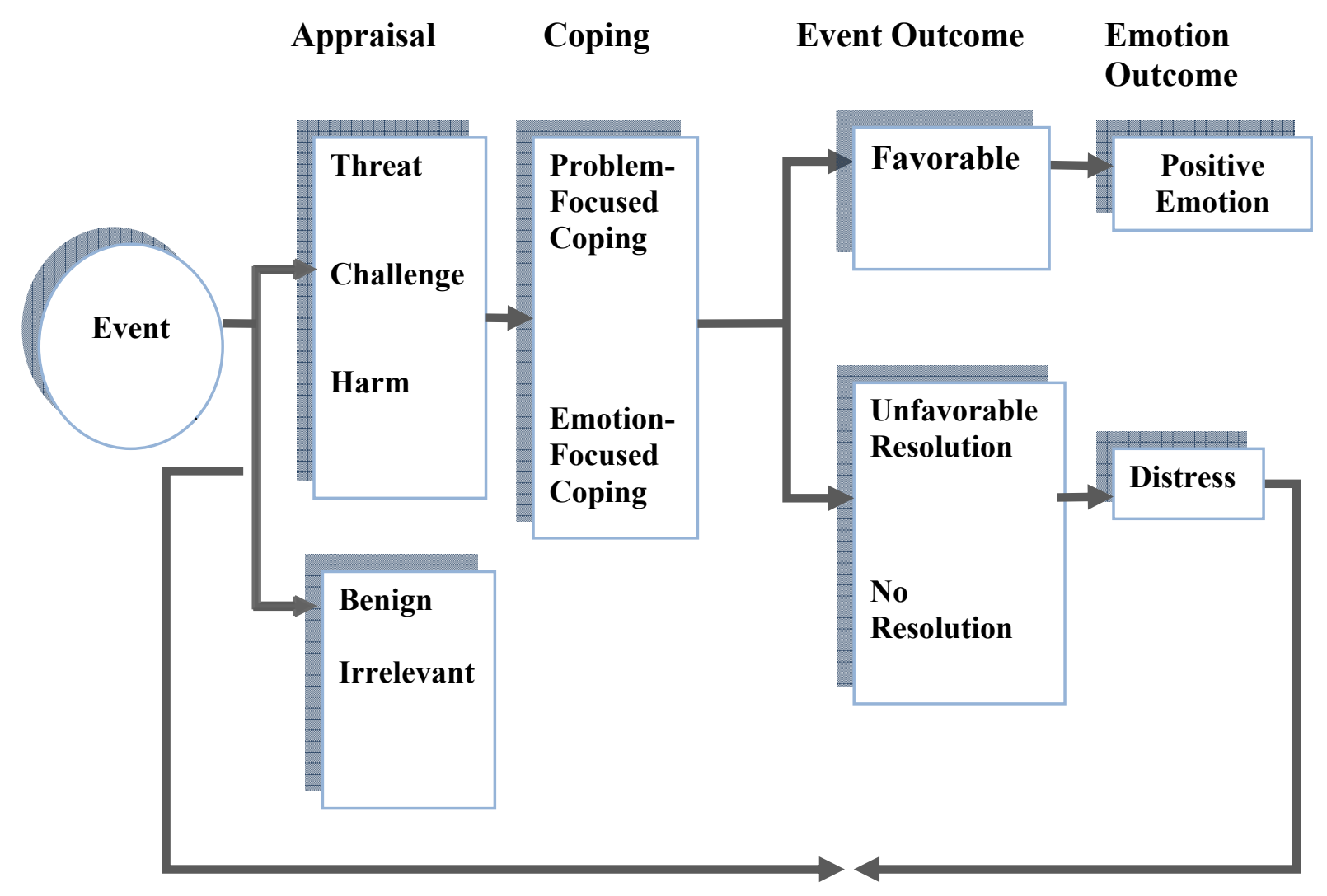

Figure 1-1. The Transactional Model of Stress and Coping

Reprinted with permission. Folkman, S., Positive psychological states and coping with severe stress. Social Science \& Medicine, 1997. 45(8): p. 1207-1221 [24]. 


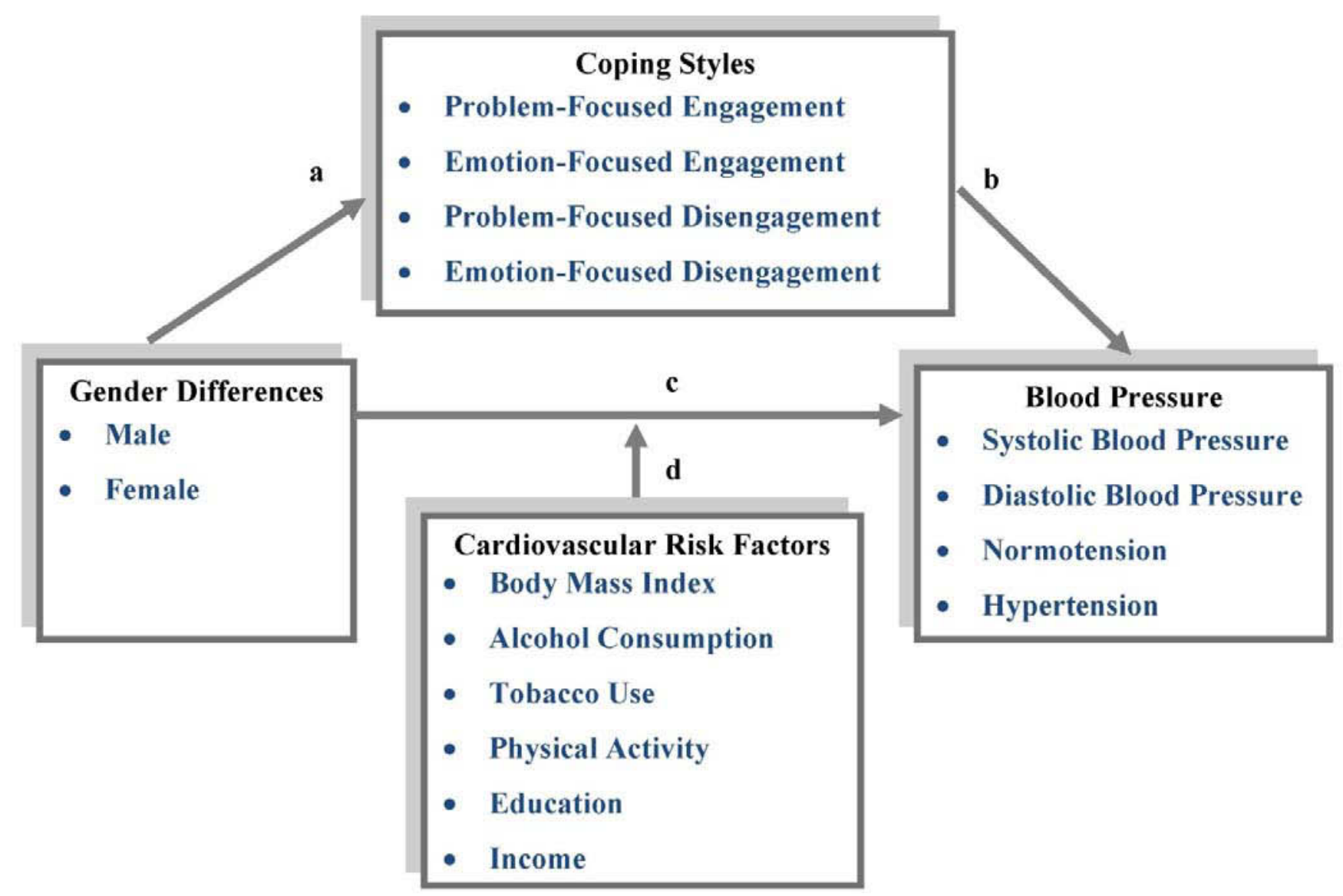

Figure 1-2. The Relationship between Gender Differences and Blood Pressure as Mediated by Cardiovascular Risk Factors

Note: a) The path between gender and coping styles.

b) The effect of the mediator coping styles on blood pressure.

c) The effect of gender on blood pressure.

d) The moderating effects of the CV risk factors on gender and blood pressure. 
home and African American men usually take care of things outside of the home [13]. However, coping styles that are inadequate when confronted with longstanding racial discrimination and high unemployment have become problematic for many African Americans putting many at risk for high blood pressure and other cardiovascular disorders $[13,31]$. Coping theorists have noted that the ability to cope decreases when there are inadequate financial, social, healthcare and familial support during stressful events. This can result in increased risky health behaviors such as over indulgence in eating, drinking, smoking, and under indulgence in physical activity. Overindulgence in eating and physical in activity contribute to obesity, as measured by BMI.

\section{Antecedents}

Preceding conditions are known as antecedents. According to Lazarus and Folkman, personal resources like education, income, and employment status may impact a person's stress level, appraisal, and available resources [6]. Socioeconomic status related to limited income and education has been attributed to increased cardiovascular disease in African Americans [32]. For example, social expectations to be employed or manage a home can become stressful and problematic with limited resources [13]. For this reason, socioeconomic status (by education and income), are identified as antecedents of coping in African Americans enrolled in the JHS.

\section{Moderators}

Moderator variables are antecedent conditions such as gender, race, age and socioeconomic status that interact to generate outcomes [33]. In addition, the directionality and strength of independent and dependent variable relationships are usually affected by moderators [33]. It is known that negative health behaviors such as physical inactivity and poor diets are associated with negative coping behaviors such as excessive alcohol consumption and smoking [32]. For instance, excessive alcohol consumption was found to be highly related to avoidant coping styles like emotional disengagement (e.g., drinking to cope) [34]. For that reason, identified moderator variables include age, SES (by education and income), body mass index (BMI), alcohol consumption, tobacco use and physical activity.

\section{Mediators}

Internal characteristics of the person or group are known as mediators [35]. The current study used JHS data to explore whether or not gender differences exist among engagement, disengagement, problem-focused engagement, problem-focused disengagement, emotion-focused engagement and emotion-focused disengagement coping styles and whether or not coping styles affect blood pressure status in JHS participants. 


\section{Definition of Key Terms}

- Alcohol Consumption: Participant's "yes" or "no" responses to amount of alcohol consumed in past 12 months.

- Blood Pressure Status: Blood pressure status referred to whether participants were hypertensive or normotensive.

- Cardiovascular Risk Factors: Refers to the behaviors used by some participants during stressful events such as excessive alcohol consumption, tobacco use, and physical inactivity.

- Coping Style: Type of coping used by participants such as engagement, disengagement, problem-focused engagement, problem-focused disengagement, emotion-focused engagement, and emotion-focused disengagement.

- Emotion-Focused Coping (EFC): Efforts made to regulate emotional responses to stressors.

- Emotion-Focused Engagement (EFE): The use of emotional expression and social support seeking behaviors to manage emotional responses during stressful situations.

- Emotion-Focused Disengagement (EFD): The use of self-criticism and social withdrawal during stressful situations.

- Engagement Coping (EC): Confronting stressors using approach-related behaviors such as problem-solving, cognitive restructuring, seeking social support, and expressing emotions.

- Disengagement Coping (DC): Using behaviors such as avoidance, wishful thinking and self criticism to limit or reduce stress.

- Gender: Refers to self-reported gender status.

- Hypertension (HTN): Blood pressure $\geq 140 / 90 \mathrm{mmHg}$ and use of blood pressure lowering medication (actual or self reported).

- Blood Pressure Controlled: Blood pressure $<140 / 90 \mathrm{~mm} \mathrm{Hg}$ while being treated.

- Blood Pressure Treatment: Taking 1 of 7 classes of antihypertensive medication.

- Normotension (NTN): A blood pressure of $<140 / 90 \mathrm{~mm} \mathrm{Hg}$ and not taking antihypertensive medication.

- Physical Activity: Usual physical activity habits in daily routine, occupation, home, yard, garden, and frequency and duration for the three most frequent sports/exercise activities performed in the past 12 months.

- Problem-Focused Coping: Efforts made to manage stressful situations.

- Problem-Focused Engagement: The use of problem-solving and cognitive restructuring behaviors to confront and manage stressful situations.

- Problem-Focused Disengagement: The use of wishful thinking and avoidance behaviors to avoid confronting stressful situations.

- Tobacco Use: Current and past usage of cigarettes, pipes, cigars, chewing tobacco, and dip/snuff. Considered a modifiable risk factor of CVD. 


\section{Assumptions}

The following assumptions were made for the purpose of the study:

1. Coping involves effort made by an individual to manage problems.

2. Coping styles mediate the relationship between gender and blood pressure.

3. Coping styles combined with excessive alcohol consumption, tobacco use, decreased physical activity and increased BMI adversely affect blood pressure.

4. Disengagement coping styles inhibit adaptive health related behaviors.

5. Ineffective coping styles negatively affect blood pressure status.

6. Women seek more social support and express more emotions than men.

7. JHS participants accurately assessed and reported their coping truthfully using a paper and pencil instrument.

\section{Strengths and Limitations}

This study has several limitations and strengths. For practicality and feasibility, secondary data was used in this study. Secondary data analysis consists of using data from a preexisting study to answer new questions [36]. However in doing so, the researcher is limited as to the type and number of research questions to ask as well as generalizability concerns. Comparatively, some strengths of using secondary data include little to no risk of harm to study participants, timeliness, and cost efficiency. A limitation in the current study consists of the use of secondary data from a single ethnic group located in a specific geographic region in the U.S. Using a single ethnicity can possibly limit generalizability to other populations and does not enable the researcher to make observations, develop new ideas or add new variables to the dataset. Another concern when using secondary data is excessive missing data [36]. The use of a correlational study design in the current study is a limitation because a cause and effect relationship may be difficult to determine since coping style is related to blood pressure over time. Instrumentation is another limitation because using one self-report measure of coping can introduce mono-method bias into the study. A major strength of the current study about the ways AAs cope can be added to existing coping literature as well as be used as a stepping stone to find preventive ways to reduce stress-related high blood pressure in African American men and women. While several coping style questions were addressed in this study, several more have been raised. Therefore, further research is recommended for coping relative to blood pressure and hypertension in African Americans. 


\section{CHAPTER 2. REVIEW OF LITERATURE}

This chapter describes literature related to coping styles relative to blood pressure. Because the Jackson Heart Study (JHS) sample consisted of only African American (AA) participants, the literature review focuses on studies about coping and blood pressure in the African American population. Past and current studies guided by the psychological theory of stress and coping developed by Lazarus and colleagues have been reviewed and are included in this chapter. The investigator conducted computer-assisted searches of MEDLINE, PUBMED, PSYCHINFO and Google databases for current articles and articles published no longer than within the past 20 years. The following keyword sets were used: African Americans and coping; African Americans, coping and blood pressure, problem-focused coping and men, problem-focused coping and African American men, problem-focused coping and women, problem-focused coping and African American women, African Americans and high blood pressure, high blood pressure and coping style, and coping style and African Americans. References from many of the articles provided additional sources and ranged from 1980 to present. The literature review is divided into three sections: coping styles; coping styles and gender; and coping styles and blood pressure.

\section{Coping Styles}

Coping styles involve thoughts and behaviors that help individuals master, lessen, and endure internal and external conflicts that occur when perceptions of personal or environmental threats, harm, or losses occur [19]. Coping has two functions. It can regulate the emotions caused by stressors, and it can manage or alter the stressors affecting the person-environment relationship [25]. Coping styles can affect health outcomes negatively when an individual uses unhealthy coping behaviors such as excessive alcohol consumption, cigarette smoking, and physical inactivity. These unhealthy behaviors, when used to decrease stress, can result in increased blood pressure [27]. Coping is the attempt to manage alterations in the person-environment relationship across time. Individuals tend to appraise stressful transactions as being threatening, challenging, or harmful. Coping processes are then implemented to either regulate emotions or regulate emotions and manage problems.

Emotion-focused coping (EFC) styles are used to regulate emotions during stressful events [23]. Emotion-focused coping was found to have highly significant positive associations with perceived stress, diabetic problem areas, and negative diabetic control appraisals in 185 African Americans with type 2 diabetes aged 59 years old [26]. However, in another study of 162 African Americans, emotion-focused coping was a strong positive associated with socioeconomic status and chronic stress emotions ( $\beta=$ $.38, \mathrm{p}<.05)$ but not with blood pressure [6]. Problem-focused coping styles (PFC) manage stressors by changing personal or environmental circumstances [22]. A study exploring coping style from an appraisal and dispositional point of view found that individuals with higher problem-solving confidence, such as better self-efficacy, used more problem-focused coping styles than individuals with less self-efficacy [37]. In a 
study of 18 adults aged 60 from the metropolitan region of Curitiba, located in Paraná, Brazil, adverse and favorable situational experiences were examined. The study investigators found that older adults use both problem- and emotion-focused coping. Seeking medical care and taking care of the body characterized problem-focused coping and seeking help from family and others symbolized emotion-focused coping [38]. The impact of coping style, stress, socioeconomic status (SES), and discrimination was examined in a multi-ethnic sample of 812 Hispanic $(n=196)$, Caucasian $(n=238)$, and African American $(\mathrm{n}=378)$ adult men and women from Miami-Dade and Duval counties. Study findings indicated that problem-focused (active) coping was associated with better self-reported health and oral health in African Americans, while low active coping, along with low SES, were associated with poorer oral health in Whites [15].

\section{Engagement and Disengagement Coping}

Coping styles can directly impact the emotional and physical consequences of stress, along with indirectly impacting stress appraisal and appraisal outcomes [26]. Numerous coping styles are identified by various theorists and researchers. The two primary coping styles are engagement and disengagement. For example engagement is sometimes described as approach or active and disengagement is sometimes described as avoidant or passive coping $[39,40]$. In the JHS cohort, engagement and disengagement coping were measured by Addison and colleagues for 4,354 participants [18]. For this reason most of the literature presented in this chapter focuses on engagement and disengagement coping styles. However, other styles are briefly reviewed in order to present a thorough discussion of coping styles in African Americans.

An engagement coping (EC) style (management of stressors) occurs when individuals use direct approaches to handle adverse situations; seek advice from family, friends, or clergy; and appropriately express feelings, thoughts, and emotions. Individuals with adequate stress management skills practice healthy behaviors such as limiting alcohol consumption, living smoke-free, and maintaining a physically active lifestyle. Comparatively, a disengagement coping (DC) style (emotion regulation) occurs when individuals seek to escape adverse situations by wishing problems would go away, by drinking and smoking to cope, or by being physically inactive. Studies have shown that ineffective coping styles, such as problem-focused disengagement or emotion-focused disengagement, increase neurochemical reactions, result in increased blood pressure, and higher morbidity. In addition, emotion-focused coping styles like denial or avoidance can inhibit adaptive health/illness-related behavior [27].

Malan et al. studied the relationship between coping and blood pressure in a Black African population. In one study of men $(n=286)$ and women $(n=380)$, findings showed that engagement coping styles increased $\beta$-adrenergic vasodilatation activity (e.g., increased catecholamine levels) and increased blood pressure via cardiac mechanisms (e.g., increased cardiac output and stroke volume) [41]. In contrast, disengagement coping styles increase $\alpha$-adrenergic vasoconstriction activity resulting in decreased changes in catecholamine and elevated blood pressure via vascular or 
peripheral mechanisms. A second study by Malan et al. of men $(n=109)$ and women $(n=$ 127) showed that cardiovascular effects of ineffective coping include increased diastolic blood pressure (DBP) during disengagement coping and increased systolic blood pressure (SBP) during engagement coping [29].

\section{Problem-Focused Engagement Coping}

Problem-focused engagement coping (PFE) combines both aggressive, cool, rational, and deliberate tactics to problem-solve, while emotion-focused disengagement coping relies on self-controlling and escape-avoidance tactics [23]. Studies have shown that the absence of drug use, higher self-esteem, and more social support are thought to be predictive of problem-focused coping [42]. Examples of problem-focused engagement coping include "I worked on solving the problems in the situation" [43] and "I look for the silver lining or try to look on the bright side of things" [18]. Comparatively, "I hope the problem will take care of itself" [18] and I went along as if nothing were happening" [43] are examples of problem-focused disengagement.

Problem-focused engagement (PFE) is the combination of cognitive restructuring and problem solving. "I worked on solving the problems in the situation" is an example of problem-focused engagement, according to Tobin [43]. PFE was found in a study by Girdler and colleagues, who assessed gender differences in hemodynamic responses to behavioral stressor in a sample of 31 participants (White $n=25$; Black $n=$ 6). Unfortunately, there were only 2 African American males and 4 AA females. The study reported that men attempted to reduce stressful threats significantly more than females $(t(27)=3.41, p<0.005)[44]$.

Studies indicate that African Americans' coping styles may be rooted in racial inequity and oppression [8, 45] James and colleagues conceptualized the disposition to strive against chronic psychological stress despite a myriad of psychosocial, environmental, and health inequities as John Henryism (JH). Inspired by a steel driver named John Henry, who in American folklore did not give up when faced with innumerable adversities [46], JH refers to a high effort or active coping style and is a form of problem-focused engagement coping [3, 12, 46-48].

\section{Problem-Focused Disengagement Coping}

There is very little to no information about PFD and African Americans in current and past coping literature. However, Stein and Nyamathi found that compared to AA men (180) and Latino men (23), women $(\mathrm{AA}=179$, Latino $=26)$ used more problem-focused disengagement $(\mathrm{z}=2.38, \mathrm{p} \leq 0.01)$ than the men [7]. 


\section{Emotion-Focused Engagement Coping}

Emotion-focused engagement coping (EFE) involves seeking the advice of family, friends, and clergy for emotional, economic, and social support during stressful events. It is also known as a collective coping style since it makes use of input collected from multiple sources [10]. Collective coping is a form of EFE, as demonstrated by the Coping Strategies Inventory Short Form (CSI-SF) item 13: "I ask a close friend or relative that I respect for help or advice" [43]. Gendered racism, psychological distress, and coping styles were investigated in over 300 African American women. Findings showed that cognitive-emotional coping partially mediated the relationship between gendered racism and global psychological distress. However, there were no effects with spiritual-, collective-, or ritual-centered coping [49]. Reliance on God, prayer, and church going has been shown to reduce adverse health consequences, stress, negative health behaviors (e.g., smoking, alcohol, drugs, unhealthy eating, etc.), and blood pressure [50]. Another form of EFE coping is religious coping. Religious coping has afforded the African American community the tenacity to maintain a level of positivity to pull through a myriad of stressors [8].

\section{Emotion-Focused Disengagement Coping}

Emotion-focused disengagement (EFD) coping or avoidance coping is characterized by problem evasion and thoughts such as "wishing problems would go away or be over with" and unhealthy behaviors like over-eating, and excessive alcohol, drug and tobacco use [25]. Russell and colleagues found a significant relationship between changes in alcohol use and blood pressure. Findings also showed in men and women that alcohol use predicted avoidance coping during stressful events [34].

\section{Coping Styles and Gender}

\section{Problem-Focused and Emotion-Focused Coping Styles and Gender}

Several studies have found that gender is associated with specific coping styles [7, 19, 51-54]. Lazarus and colleagues suggested that men use more problem-focused coping than women, especially during work-related stress [19]. Another study of 100 White protestants ( $n=48$ men, $n=52$ women), found that men tended to use more problemfocused coping (PFC) than women, yet there were no gender differences noted in emotion-focused coping [19].

Emotion-focused coping (EFC) was preferred more in females $(n=216)$ than males $(n=95)$ in a study that investigated gender, negative affectivity, stressor appraisal and coping style. Emotion-focused, problem-focused and avoidant coping styles were examined with and without controlling for perceived stressfulness. Findings for emotionfocused coping, English as a first language and perceived stressfulness $[F(2,204)=$ $69.62, p<.001]$ indicated that females favor emotion-focused coping styles more than 
men. Comparatively, analysis of emotion-focused coping and English as a first language $(r=.15, p<.05)$ without perceived stressfulness also showed that females favor emotionfocus coping styles [55].

\section{Emotion-Focused Disengagement Coping Styles and Men}

Relationships among stress, coping, and health risk behavior were investigated in a sample of 621 African American and Hispanic homeless women. The findings showed a significant gender difference in the relationship between avoidant behavior and escapist drug use (correlation for men $=0.30$, for women $=0.17$ ) [56]. In other words, avoidant or emotion-focused disengagement coping was associated with increased drug use in men [56]. Inhibitory-passive coping and active coping challenges were evaluated in a sample of 24 African American men, 22 African American women, 49 Caucasian men and 43 Caucasian women. Increased vascular indices were descriptive of inhibitory-passive coping challenges, and increased myocardial indices described active coping challenges. Findings indicated that African American men demonstrated more inhibitory-passive coping $(F(1,134)=4.29, p=.04)$, hostility, pessimism, and less social support than African American women and Caucasian men and women. Assessment of inhibitorypassive coping using the Coping Orientation to Problems Encountered (COPE) indicated detached, uninvolved, passive coping in AA men [57]. Therefore, inhibitory-passive coping is reflective of an emotion-focused disengagement coping style.

\section{Emotion-Focused Disengagement Coping Styles and Women}

Stein and Nyamathi examined relationships among stress, coping, and risky health behaviors in 408 African American and Latin American adults. Avoidant coping, an emotion-focused disengagement coping style, was reported more in 179 African American women (87.3\%) and 26 Latina women (12.7\%) than in 180 African American men (88.7\%) and 23 Latino men (11.3\%) [56]. Another study reported a greater preference for avoidant coping in African American women compared to African American men in a study that examined the effects of racism and coping styles $F(2,137)$ $=3.77, p<.05$. The study also indicated that women compared to men more often, sought more social support $(12.24 \pm 5.46)$ versus $(10.06 \pm 5.46)$, respectively, $\mathrm{p}<.05$ [56].

\section{Problem-Focused Engagement Coping Styles and Women}

A qualitative study examined stress related heart disease in a sample of 12 African American women aged 50 to 73 years old. Participants viewed stress as the primary cause of a "bad heart"; therefore, use of the phrase "not worrying" about a "bad heart" indicated an emotion-focused coping style was emerging. However, findings revealed that participants viewed worrying about a "bad heart" as causing more health 
problems than "not worrying," which reflected an active problem-focused engagement coping style [10].

Strickland and associates examined relationships among coping, stress, social support, and weight class and found that confrontive coping was used more in $43.8 \%$ of 178 premenopausal African American women. The researchers also indicated that fewer overweight premenopausal African American women confronted their problems compared to women with normal weight [58]. According to Lazarus and Folkman, confrontive coping is a problem-focused engagement coping style [59]. Examples of confrontive coping include "stood my ground and fought for what I wanted" and "tried to get the person responsible to change his or her mind" [59].

\section{Coping Styles and Blood Pressure}

\section{Emotion-Focused Coping Styles and Blood Pressure}

Suppressed anger is a known cause of greater cardiovascular reactivity among African Americans than in European Americans [60-63]. Harburg and colleagues characterized anger coping styles as anger-in or anger-out [14]. Suppressed anger is referred to as anger-in, and expressed anger is referred to as anger-out [14]. Anger-in behaviors includes withdrawing from people, pouting or sulking, becoming angrier than willing to admit, and holding grudges [14]. Comparatively, anger-out behaviors consists of door slamming, saying nasty things, arguing with others, and striking out at others [14]. Additionally, analyses of blood pressure and psychological coping in 158 Italian men and women revealed an inverse relationship between emotion-focused coping and BP in men only suggesting that seeking external support (i.e., a problem-focused coping style) may be a source of stress for some men [64].

\section{Emotion-Focused Engagement Coping Styles and Blood Pressure}

Letting emotions out, as with anger-out, is a form of emotion-focused engagement, whereas avoiding and criticizing behaviors are forms of emotion-focused disengagement [43]. For instance, Harburg and colleagues examined anger coping styles in African American $(n=371)$ and Caucasian men $(n=349)$ from 18 to over 40 years of age. Findings showed that older Black and White men with higher anger-out scores had higher blood pressures than men who did not have high anger-out scores [14]. Also, there was not a significant relationship between anger-in and blood pressure [14]. Another study examined the effects of race, sex, socio-ecological stress, and habitual anger coping styles on SBP and DBP in African Americans and White men and women. Findings indicated that anger expression was related to higher DBP in African American females $(\mathrm{n}=173)$ than African American males $(252)$ and Whites $($ men $=240$; women $=79),(F=$ 3.91, $d f=1 / 980, p=0.05$ ) [17]. 
Religious coping, an emotion-focused engagement coping style, consists of personal coping activities such as prayer, studying bible scriptures, attending church services and seeking religious help [50]. Steffen and associates investigated religious coping, ethnicity, and ambulatory BP in African Americans $(n=77)$ and White Americans $(n=76)$ along with clinic and day-time blood pressure. Findings showed an association between religious coping and lower blood pressure among African Americans but not among White Americans [50]. High religious coping was associated with awake ambulatory blood pressure $(p<.05)$ and sleep ambulatory blood pressure $(p<.01)$ [50]. An emotion-focused engagement style was found to be used frequently by AAs participating in a study that examined racism, chronic stress emotions, and blood pressure. The sample consisted of young (mean age $42.65 \pm 17.72$ ), healthy adult African American men $(n=29)$ and women $(n=133)$ from 18 to 80 years old. The majority of the sample had no history of hypertension $(\mathrm{n}=116,72 \%)$. Findings showed that $18 \%(\mathrm{n}$ $=30)$ used EFE and $47 \%(n=76)$ indicated limited use of the EFE coping style [6]. Also, EFC was significantly related to SES and chronic stress emotions $(\beta=.38, p<.05)$ but not to BP [6].

\section{Problem-Focused Coping Styles and Blood Pressure}

Subjective stress and coping resources on blood pressure reactivity were examined in a sample of 69 African American men and women. Findings showed that the use of problem-focused coping during subjective stress predicted higher diastolic blood pressure reactivity in men $(35.58 \pm 6.32)$ compared to women $(31.5 \pm 6.36), t(67)=2.38$, $p=.02$ and that subjective stress was not significantly related to SBP reactivity $(r=-.12$, $p=.30)$ or DBP reactivity $(r=-.06, p=.60)$ in men and women [2].

\section{Problem-Focused Engagement Coping Styles and Blood Pressure}

Problem-focused engagement coping such as "I went along as if nothing were happening" [43] was also evident in a study conducted by Krieger and Sidney [65]. Findings showed that African American women had 4mmHg higher SBPs compared to African American men and white men and women. The researchers reported that the African American women responded to racial discrimination by keeping it to themselves versus talking about it to others or trying to do something about it [65].

As previously stated, $\mathrm{JH}$ is a problem-focused engagement coping style.

Research regarding John Henryism indicates that working hard and not giving up during stress is more strongly related to hypertension in African Americans than in European Americans [46-48]. The John Henryism Scale for Active Coping (JHAC) is a 12-item instrument developed by James to measure $\mathrm{JH}$ [46]. Interactions between gender, John Henryism, and arterial blood pressure were examined in a sample of 600 African Americans using the JHAC. Findings indicated that high John Henryism was associated with higher blood pressure and increased hypertension risks in men. Consequently, women with high John Henryism, had lower blood pressure and decreased hypertension 
risks [13]. Researchers Fernander and colleagues also examined JH in a sample of 83 urban African American men and 64 urban African American women using the 12-item JHAC. Findings indicated relationships between high JH and high BP in women with low SES and high JH and high BP in men with high SES [3].

\section{Summary of Review of Literature}

There is limited information about the relationships among coping styles and blood pressure in African Americans. In the studies found, there is preliminary evidence of a significant association between coping style and blood pressure. In addition, the association may vary by gender. Consequently, a significant gap in the literature exists because African American participation in this area of research has been limited and no studies found used the CSI-SF to characterized the coping styles. However, other coping instruments were used to determine coping style in African Americans such as the COPE Questionnaire [21, 41, 50, 66], the Medical Outcomes Study, the Modes of Coping Battery, John Henry Scale for Active Coping (JHAC 12) [3, 15, 67], Emotional Approach Coping Scale [6], and the Jalowiec Coping Scale [53]. In spite of this, a deficit exists about African American coping styles. This may be reflective of the small samples used in many existing studies. Therefore, a major goal of this study was to gain an increased understanding of coping style and its relationship to blood pressure and hypertension among African Americans. Fortunately, the JHS cohort is a large cohort of participants that can be used to further address this critical gap in the literature. The JHS database is a rich source of data to explore the relationship between coping and blood pressure. Within the JHS data there is a high prevalence of HTN in African Americans. In a sample of men $(\mathrm{n}=1154)$ and women $(\mathrm{n}=2148)$ aged 21-94, JHS investigators found an overall prevalence rate of hypertension of $62.9 \%$, a treatment rate of $83.2 \%$ among those aware of their hypertension status and a control rate of $66.4 \%$ among those treated with antihypertensive medications [68].

Thus, the JHS data was sought for this research. Differing coping styles among African Americans may be related to racial oppression and health disparities experienced within this population. As a result, a stronghold of collective resiliency, family and church reliance emerged. The tendency of some African American women to be "a strong woman" may be an example of an engagement style and can also be a stressor within itself [10]. Comparatively, African American men have long believed that obstacles can be overcome as long as they focus and work hard [13]. On the contrary, studies have shown that an engagement style (e.g., John Henryism) can adversely affect blood pressure status in African American during chronic stress [46]. These documented differences in coping styles in African American men and women are indicative of the gaps in coping literature and of the need for exploration of these coping differences between genders in the JHS. These studies give preliminary evidence of an association between coping style and blood pressure in African Americans.

Review of coping literature revealed extensive gaps in research regarding

engagement, disengagement, problem-focused and emotion-focused coping styles, and 
African Americans. There is very limited information about problem-focused disengagement coping in African and White Americans and limited information about religious, collective, anger, and John Henryism coping styles in White Americans. 


\section{CHAPTER 3. METHODS}

This study explored coping style, blood pressure, gender, and associated health behaviors in men and women enrolled in the Jackson Heart Study. This methodology chapter reports a description of the setting, sample, instruments, procedures, and statistical analyses used to speak to the aims and research questions of the study.

\section{Research Design}

This was a descriptive correlational study that used secondary data from the Jackson Heart Study. The JHS is a community-based, observational study of African Americans residing in the MSA of Jackson, MS. This study design focused on the relationship of coping styles with measures of blood pressure stratified by gender. The dependent variables for this study were mean systolic blood pressure, mean diastolic blood pressure, normotension, and hypertension. The independent variables were problem-focused engagement, problem-focused disengagement, emotion-focused engagement, and emotion-focused disengagement total scores. Co-variates for the study included alcohol consumption, tobacco use, physical activity, socioeconomic status (e.g., income and education), and BMI collected during JHS examination 1 from 2000 to 2004.

\section{Sample and Setting}

For the JHS, a sample of 5,301 African American men and women aged 35 to 84 were recruited from the metropolitan statistical area of Jackson, MS, from September 2000 to March 2004. The sample for this study consisted of 4,354 men $(n=1,557)$ and women $(\mathrm{n}=2,797)$ who participated in the JHS between 2000 and 2004. Participants were excluded if they did not complete the CSI-SF and had no available systolic and diastolic blood pressure data. JHS exclusion criteria included a history of psychiatric illness, terminal illness, dialysis, absence of blood pressure measurement, or lack of medication information or participant consent [5].

\section{JHS Procedure for Data Collection on Coping Styles, Blood Pressure, Body Mass Index, Alcohol and Tobacco Use, Physical Activity, and Socioeconomic Status}

Components of the JHS research design consisted of enumeration, home interview, examination 1, follow-up examination and clinical review, and diagnostic classification. Enumeration entailed completing household rosters of all selected participants aged 35-84, followed by the home induction interview (HII) (Table 3-1). First, informed consent, personal and family health history, and information about stress, tobacco use, physical activity, social support, and socioeconomic status was obtained by JHS interviewers [69]. Next, participants were given written and verbal descriptions of the JHS and instructed to complete the Approach to Life booklet which contained three 
Table 3-1. Components of Jackson Heart Study Examination

\begin{tabular}{ll}
\hline Procedure & \multicolumn{1}{c}{ Description } \\
\hline Reception & $\begin{array}{l}\text { Greet the participant, determine fasting status, obtain tracking data, and } \\
\text { collect medications. }\end{array}$ \\
$\begin{array}{l}\text { Informed } \\
\text { Consent }\end{array}$ & Obtain informed consent. \\
Blood & Obtain sitting blood pressure, ankle and arm. \\
Intervire & $\begin{array}{l}\text { Collect medical/health history (medication survey, medical history, stroke } \\
\text { symptoms, reproductive history, family structure, diet food frequency), } \\
\text { and sociocultural history (discrimination and alcohol/drugs). }\end{array}$ \\
& $\begin{array}{l}\text { Provide instructions on 48-hr urine collection, 24-hr exam procedures } \\
\text { (urine collection, ambulatory blood pressure monitoring), sub-studies (diet } \\
\text { and physical activity) and take home (Hassels and Mood Inventory, }\end{array}$ \\
Interview & $\begin{array}{l}\text { Weekly Stress Inventory (WSI), Center for Epidemiologic Studies } \\
\text { Depression Scale (CED-D), Composite Hostility Score (CHOST) and the } \\
\text { Spielberger Anger Expression Inventory (STAXI). Thank participant. }\end{array}$ \\
\hline
\end{tabular}

Modified with permission. Jackson Heart Study Investigators, General description and study management visit 1, in Manual 1, The Jackson Heart Study, Editor. 2003, Jackson, MS: Jackson Heart Study Coordinating Center, p. 20 [70]. 
separate measures for assessing social support, coping and religion, and religious coping [69]. The JHS used the Approach to Life A 16-item: Interpersonal Support Evaluation List (ISL) to evaluate (a) emotional support (Appraisal), (b) others with whom one can interact (Belonging), (c) material aid (Tangible), and (d) others with which one believes she or he compares favorably (Self-esteem) [69]. Coping was measured using the Approach to Life B: Coping Strategies Inventory Short Form (CSI-SF). Each participant was given the 15-item CSI-SF at the conclusion of the home induction interview as part of the Approach to Life booklet in the Bring to Clinic section [71] and was instructed to complete and return the form at the next clinic visit.

Upon completion of the home induction interview, participants were instructed to bring all prescription and nonprescription medications taken within two weeks of their clinic appointment. The participants were instructed to avoid eating and drinking 12 hours prior to their clinic appointment and to abstain from alcohol and tobacco use (Table 3-2). Prior to obtaining two sitting blood pressure measurements, participants were instructed to take usually prescribed antihypertensive medications before coming to the clinic. A random zero sphygmomanometer was used to measure sitting blood pressure $[70]$.

\section{Informed Consent}

Participants were asked for consent for participation in the JHS before administration of all data collection instruments. Individuals with visual or hearing impairments were provided with written, audio and visual consent forms and, if needed, the consent documents were read to the individual. Ample time was provided for reading and signing of consent documents. A copy of the original consent document, including the signature page, was given to the participant, and original consent documents were placed in the participant's JHS file [69]. JHS participants signed separate consent forms for management of personal medical records, study results, genetic research participation and genetic research non-participation. The JHS consent form also included a definition of whether the research was to be limited to JHS "focus diseases" only and the level of sample and data accessibility of non-JHS investigators [72].

\section{Approval}

Permission to conduct the proposed study was obtained from the University of Tennessee Health Science Center's Institutional Review Board (IRB). The study was reviewed as exempt, according to the IRB approval letter (Appendix A). Additionally, prior written approval to use the Jackson Heart Study data was obtained (Appendix B). 
Table 3-2. The Jackson Heart Study Home Induction Interview

\begin{tabular}{ll}
\hline Section & \multicolumn{1}{c}{ Purpose } \\
\hline Informed Consent & Obtain informed consent. \\
Health Status & Obtain general knowledge of the participant's health status. \\
Risk Factors & Determine prior hospitalizations within the past year. \\
Family Medical History & $\begin{array}{l}\text { Determine selected risk factors for cardiovascular disease } \\
\text { (CVD). }\end{array}$ \\
& $\begin{array}{l}\text { Obtain general knowledge of the participant's family health } \\
\text { status; determine past history of cause of death due to } \\
\text { CVD, cancer or diabetes. }\end{array}$ \\
Smoking & $\begin{array}{l}\text { Determine smoking status and amount and frequency. } \\
\text { Employment }\end{array}$ \\
Determine the participant's current employment status. \\
\hline
\end{tabular}

Modified with permission. Jackson Heart Study Investigators, Protocol and manuals of operation, in Manual 2: Cohort procedures, The Jackson Heart Study, Editor. 2001, Jackson, MS: Jackson Heart Study Coordinating Center, p. 39 [69]. 


\section{Measures}

\section{Measure of Coping Style}

Coping style was the independent variable in this study. Coping style was measured using the Coping Strategies Inventory Short Form (CSI-SF), a four-factor 16item instrument developed to measure coping responses in the JHS cohort. The CSI-SF (Table 3-3) has a two-level subscale format. The first level consists of two subscalesengagement and disengagement and the second level consists of the following four subscales: problem-focused engagement (PFE), problem-focused disengagement (PFD), emotion-focused engagement (EFE) and emotion-focused disengagement (EFD) [18]. Each item was evaluated using a 5-point Likert Scale that ranged from 1 (never), 2 (seldom), 3 (sometimes), 4 (often), and 5 (almost always). Scoring consisted of summarized responses to items contained in each subscale with minimum scores ranging from 4 to 20 [71]. Reliability for each subscale ranged from marginal to acceptable in the JHS cohort. Cronbach's alpha-reliability was 0.59-0.70 for the engagement and disengagement scales and 0.58-0.72 for subscales PFE, PFD, EFE and EFD [18].

\section{Measure of Sitting Blood Pressure}

Blood pressure was the dependent variable. Three measures for BP from JHS data were used for this study: mean systolic and diastolic blood pressures, normotension, and hypertension. In the JHS, trained personnel using a Hawksley random zero sphygmomanometer measured blood pressure. Cuff size was determined by arm circumference. Two sitting blood pressure measurements, taken 1-minute apart, were averaged to obtain the systolic and diastolic BP. Blood pressure was categorized as normal, pre-hypertensive, hypertension stage I, and hypertension stage II using the Joint National Committee on Prevention, Detection, Evaluation, and Treatment of High Blood Pressure Seventh Report (JNC7) blood pressure classifications [68]. In the JHS, a blood pressure of $<140 / 90 \mathrm{~mm} \mathrm{Hg}$ with no history of taking antihypertensive medication was defined as normotension. Comparatively, hypertension was defined as systolic blood pressure $\geq 140 \mathrm{~mm} \mathrm{Hg}$, diastolic blood pressure $\geq 90 \mathrm{~mm} \mathrm{Hg}$, or history of taking antihypertensive medication (actual or self-reported) regardless of blood pressure readings [5]. The JHS classified blood pressure according to the standards set by the Joint National Committee on Prevention, Detection, Evaluation, and Treatment of High Blood Pressure Seventh Report (JNC7) as normal (<120/80 mm Hg), pre-hypertension (120/80 to $139 / 89 \mathrm{~mm} \mathrm{Hg}$ ), stage 1 hypertension (140 to 159/90 to $99 \mathrm{~mm} \mathrm{Hg}$ ), or stage 2 hypertension ( $\geq 160 / 100 \mathrm{~mm} \mathrm{Hg}$ ) [73]. The JHS also classified hypertensive participants according to whether or not they were treated or controlled. Treatment was defined as taking 1 of 7 classes of antihypertensive medication and blood pressure $<140 / 90 \mathrm{~mm} \mathrm{Hg}$, while being treated was defined as control [5]. 
Table 3-3. The Coping Strategies Inventory Short-Form Subscales

\begin{tabular}{lll}
\hline Coping Style & & \multicolumn{1}{c}{ CSI-SF Items } \\
\hline Problem-Focused & $\# 2$ & I make a plan of action and follow it. \\
Engagement & $\begin{array}{l}\text { I look for the silver lining or try to put things into } \\
\text { perspective. }\end{array}$ \\
& $\# 8$ & I tackle the problem head on. \\
& I step back from the situation and try to put things \\
& into perspective. \\
Problem-Focused & $\# 4$ & I hope the problem will take care of itself. \\
Disengagement & $\# 12$ & I try to put the problem out of my mind. \\
& $\# 14$ & I try not to think about the problem. \\
& $\# 5$ & I let my emotions out. \\
Emotion-Focused & I try to talk about it with a friend or family. \\
Engagement & $\# 11$ & I let my feelings out to reduce the stress. \\
& $\# 13$ & I ask a close friend or relative that I respect for \\
& help or advice. \\
& $\# 3$ & I try to spend time alone. \\
$\# 10$ & I tend to blame myself. \\
$\# 15$ & I tend to criticize myself. \\
$\# 16$ & I keep my thoughts and feelings to myself. \\
&
\end{tabular}

Adapted with permission. Jackson Heart Study Investigators, Protocol and manuals of operation in Manual 2: Cohort procedures, The Jackson Heart Study, Editor. 2001. Jackson, MS: Jackson Heart Study Coordinating Center, p. 39 [69]. 


\section{Measure of Physical Activity}

The Physical Activity (PACA) 30-item questionnaire assesses active living, work, sport, and home and family life. Participants were asked to respond to a combination of yes/no and 5-point Likert-type questions [74]. Physical activity variables included total scores from the 1) active living index, which contained seven questions related to his or her usual daily routine, 2) the work index, which contained eight items about workrelated activity, 3) the sport index, which contained eight questions regarding the occurrence and amount for three of the most sports/exercise activities performed in the past year, and 4) the home and family life index, which consisted of seven questions related to home and family-life activities. The sum of the four index scores comprises the physical activity total score [5].

\section{Measure of Alcohol Consumption}

Alcohol and drug use was measured using the Health Practices: Alcohol and Drug Use form (ADRA), which consists of five alcohol consumption-related items and three drug-use items. The 8-item instrument consists of a combination of yes/no, fill-in the blank, and Likert-type questions. Alcohol consumption variables for the current study consist of 1) alcohol drinking in the past 12 months (yes or no), 2) alcohol drinking classification I (based on number of drinks per week), and 3 ) alcohol drinking classification II (based on the number of drinks per day, age and gender) $[69,75]$. In this study, the variable alcohol consumption was measured using the alcohol drinking in the past 12 months.

\section{Measure of Body Mass Index}

Body mass index (BMI) was calculated as weight $(\mathrm{kg})$ divided by height squared $\left(\mathrm{m}^{2}\right)$. BMI, according to BMI categorization, is defined as normal $(\mathrm{BMI}<25)$, overweight $(25 \leq \mathrm{BMI}<30)$, or obese $(\mathrm{BMI} \geq 30)$ in the JHS cohort [69]. A balance scale was used to record weight to the nearest kilogram. Participants were asked to stand with heels and back of the head touching a vertical centimeter ruler. Linear measurements of the abdominal girth were obtained horizontally at the umbilicus and recorded to the nearest centimeter [72].

\section{Measure of Tobacco Use}

The Health Practices: Tobacco Use (TOBA) tool assessed environmental tobacco smoke exposure and nicotine dependence for participants who smoked cigarettes. The TOBA form included 29 various questions related to cigarettes, pipes, cigars, chewing tobacco and dip/snuff. Participants were asked various open-ended questions and ratingstype questions related to frequency, amount, etc. [69]. The tobacco use variable for this study was cigarette use only. 


\section{Measure of Demographic/Socioeconomic Data}

Demographic information such as marital, educational, and employment status was derived from the 32-item Personal Data: Socioeconomic form. Current demographic variables included education, age at home induction, and birth date. Educational categories included less than high school; high school; some or completed vocational or some college; and associate degree, college degree, and post-college. Income level classifications were based on poverty levels for years 2000-2004 family size, family income derived variable, and year of the PDSA form. Income levels included poor, lower-middle, middle-upper, and affluent [75].

\section{Statistical Analysis}

This study focused on the relationship between coping styles and blood pressure stratified by gender with covariates (i.e., age, BMI, education, income, alcohol consumption, tobacco usage, and physical activity). Descriptive statistics were generated to describe the sample and the distribution of the dependent, independent, and covariates. All analyses were conducted using Statistical Package for the Social Sciences (SPSS) software (Predictive Analytic Software (PASW) Version 18.0, IBM: Chicago, IL). The dependent variables in the current study were SBP, DBP, normotension, and hypertension. The independent variable was gender; the mediator independent variables were problem-focused and emotion-focused engagement, problem-focus and emotionfocus disengagement, total engagement and total disengagement coping; and the moderator independent variables were age, income, education, BMI, alcohol consumption, tobacco use, and physical activity. For Aim One, means and standard deviations were generated for the total CSF scale as well as for each subscale. For Aim Two, Pearson's product-moment correlation coefficient analysis was computed to assess the relationships between coping style and blood pressure. Independent sample t-tests were generated to identify gender differences in coping style, and linear regression models were generated to determine whether age, education, income, BMI, alcohol consumption, and tobacco use act as moderators for gender differences in coping style in JHS men and women. For Aim Three, stepwise multiple regressions (both linear and logistic) were used to determine the associations among engagement, disengagement, problem- and emotion-focused engagement, problem- and emotion-focused disengagement, SBP, DBP, normotension, and hypertension while controlling for the covariates [76]. These data were used to describe the sample and were included in the regression models as co-variates. To test for mediation, Sobel mediation analysis was conducted. All inferential statistics were performed at a significance level of 0.05 .

\section{Mediation and Moderator Effects}

According to Baron and Kenny, mediators explain relationships between independent and outcome variables [33], and moderators affect the direction of the relationships between independent and outcome variables [33]. The study established 
mediation as indicated by the four steps outlined by Baron and Kenny [33]. To establish the first criteria for mediation, the independent gender variable must affect the coping mediator variables. To establish the second mediation criteria, the independent gender variable must affect the dependent blood pressure variables, and thirdly, the mediator coping variables must affect the dependent blood pressure variables [33].

According to Bennett, moderator effects are tested in two steps [35]. The first step involves entering the moderator independent variables into the regression model.

Independent moderator variables for this study included gender, age, education, income, BMI, alcohol consumption, tobacco use, and physical activity. Secondly, an interaction term, which is the product of two independent variables that represent the moderator effect, is entered. Examples of interaction terms include gender $\mathrm{x}$ education $\mathrm{x}$ income, gender $\mathrm{x}$ BMI, gender $\mathrm{x}$ alcohol consumption, gender $\mathrm{x}$ tobacco and gender $\mathrm{x}$ physical activity. A moderator effect occurs when interaction terms explain a significant amount of the variance in dependent variables [35]. 


\section{CHAPTER 4. RESULTS}

There were three aims for this study. To begin with, the investigator looked at how coping style was characterized in the Jackson Heart Study. Next, the investigator aimed to explore whether or not there were coping differences among the men and women enrolled in the JHS cohort. Lastly the investigator explored whether or not there was a relationship between hypertension and coping style. Therefore, this chapter contains the results and discussion sections for this dissertation, as well as background material presented in other chapters. This chapter begins with an overview of coping styles relative to blood pressure and hypertension in African Americans.

\section{Introduction}

Coping styles used by African American men and women may be associated with health outcomes such as high blood pressure $[16,17]$. Even though many studies have explored coping in association with psychological stress and high blood pressure, few studies have examined the relationship between coping style, gender differences, and behaviors that may predispose African Americans to increased cardiovascular risks. The purpose of this study was to explore the relationship between coping style and blood pressure in African Americans using data from the Jackson Heart Study (JHS). In addition, the study sought to examine the mediating affects of coping style and the moderating affects of alcohol consumption, tobacco use, and physical activity on blood pressure.

\section{Background and Significance}

African Americans have the highest prevalence of hypertension [1-4] and the lowest blood pressure control rates of any ethnic groups in the United States [5]. Stressful life events within the African American community are well documented [6-11], and ineffective coping with these life events is thought to lead to increased blood pressure [1$3,6,12-15]$. Even though many studies have explored coping in association with psychological stress and high blood pressure, few studies have examined the relationship between coping style, gender differences, and behaviors that may predispose African Americans to increased cardiovascular risks. Consequently, limited minority research led to this secondary data analysis of coping style and blood pressure in African Americans enrolled in the JHS.

The over-arching significance of this study is that information obtained provides insight into the coping styles of African American men and women. Results will determine whether specific coping styles positively or negatively contribute to elevated blood pressure and hypertension in African Americans in the study sample. Identification of effective and ineffective coping styles as well as teaching effective coping could be 
important, low-cost approaches that could help manage blood pressure among African Americans living in the southeast region of the United States.

Coping style involves the thoughts and behaviors that help individuals master, lessen, and endure internal and external conflicts that occur when perceptions of personal or environmental threats, harm, or losses occur [19]. Coping has two functions. It can regulate the emotions caused by stressors, and it can manage or alter the stressors affecting the person-environment relationship [25]. Coping styles can affect health outcomes negatively when an individual uses unhealthy coping behaviors such as excessive alcohol consumption, cigarette smoking, and physical inactivity. These unhealthy behaviors, when used to decrease stress, can result in increased blood pressure [27]. Coping can also be used as an attempt to manage alterations in the personenvironment relationship across time. Individuals tend to appraise stressful transactions as being threatening, challenging, or harmful. Coping processes are then implemented to either regulate emotions or regulate emotions and manage problems. For example, an engagement coping (EC) style (management of stressors) occurs when individuals use direct approaches to handle adverse situations; seek advice from family, friends, or clergy; and appropriately express feelings thoughts and emotions. Individuals with adequate stress management skills practice healthy behaviors such as limiting alcohol consumption, living smoke-free, and maintaining a physically active lifestyle.

Comparatively, a disengagement coping (DC) style occurs when individuals seek to escape adverse situations by wishing problems would go away, or by drinking and smoking to cope, or by being physically inactive.

Engagement and disengagement have been further categorized as either problemfocused or emotion-focused coping [19]. Problem-focused engagement coping (PFE) combines aggressive, cool, rational and deliberate tactics to problem-solve while emotion-focused disengagement coping relies on self-controlling and escape-avoidance type tactics [23]. Emotion-focused engagement coping (EFE) involve seeking the advice of family, friends and clergy for emotional, economic and social support during stressful events. It is also known as a collective coping style since it makes use of input collected from multiple sources [10]. Emotion-focused disengagement (EFD) coping or avoidance coping, is characterized by problem evasion and thoughts such as "wishing problems would go away or be over with" and unhealthy behaviors like over-eating and excessive alcohol, drug and tobacco use [25].

\section{Research Questions}

1. How is engagement coping characterized?

2. How is disengagement coping characterized?

3 . Is engagement characterized by gender?

4. Is disengagement characterized by gender?

5. What is the relationship between coping styles and systolic blood pressure among African American men and women adjusted and unadjusted for age, tobacco use, physical activity and alcohol consumption? 
6. What is the relationship between coping styles and diastolic blood pressure among African American men and women adjusted and unadjusted for age, tobacco, physical activity and alcohol consumption?

7. What is the relationship between coping style and blood pressure control in African American men and women?

8. What is the relationship between coping style and hypertension in African American men and women?

\section{Specific Aims}

- Aim One: To characterize coping styles used by African Americans.

- Aim Two: To assess gender differences in coping styles of African Americans.

- Aim Three: To Determine the Relationship between Coping Style and Hypertension in African Americans.

\section{Conceptual Model}

Stressful life events within the African-American community are well documented, and ineffective coping with these life events is thought to contribute to increased blood pressure [21]. It has been reported elsewhere that coping styles have mediating effects. Figure 1-2 illustrates a) the path between the independent variable (gender) and the mediator variable (coping styles); b) the effect of the mediator (coping styles) on blood pressure; c) the effect of gender on blood pressure; and d) the moderating effects of health behaviors on gender and blood pressure. Blood pressure variables include: SBP, DBP, normotension $(<140 / 90$ and no history of taking antihypertension medication), and hypertension ( $\mathrm{SBP} \geq 140 \mathrm{~mm} \mathrm{Hg}, \mathrm{DBP} \geq 90 \mathrm{~mm} \mathrm{Hg}$, or history of taking anti-hypertension medications) [5].

Coping can affect health outcomes negatively when individuals use unhealthy coping behaviors such as excessive alcohol consumption, cigarette smoking, and physical inactivity. The disproportion of caloric intake in relation to physical activity leads to weight gain, which can be measured by body weight in proportion to height, known as Body Mass Index (BMI) [30]. These unhealthy behaviors, which, when used to decrease stress, may be reflective of emotion-focused coping styles, which can result in increased blood pressure [27].

The model implies that role differences, stressors, and coping styles may influence hypertension status in African American men and women enrolled in the JHS. Culturally, many African American families share dual responsibilities. African American women are usually responsible for taking care of things related to inside of the home and African American men usually take care of things outside of the home. However, inadequate coping styles along with longstanding racial discrimination and high unemployment have become problematic for many African Americans, putting many at risk for high blood pressure and other cardiovascular disorders [13, 31]. Coping 
theorists have noted that the ability to cope decreases when there are inadequate financial, social, healthcare, and familial support during stressful events. This can result in increased risky health behaviors such as over indulgence in eating, drinking, smoking, and under indulgence in physical activity. Overindulgence in eating and physical in activity contribute to obesity, as measured by BMI. These inadequate coping strategies can lead to increased blood pressure.

\section{Methods}

A cross sectional secondary data analysis design was used to examine the relationship of coping styles and blood pressure in African American men and women who participated in the JHS. The JHS is a community-based, observational study of African Americans residing in the MSA of Jackson, MS. The sample for this study consisted of 4,354 men $(1,557)$ and women $(2,797)$ who participated in the JHS between 2000 and 2004. Participants were included in this study if they completed the CSI-SF and had systolic and diastolic data available.

\section{Study Measures}

Blood pressure (BP) was the dependent variable for this study. Four measures of BP were used: mean systolic and diastolic blood pressures, normotension and hypertension. Also in the JHS, blood pressure was measured by trained personnel using a Hawksley random zero sphygmomanometer (Hawksley and Sons Ltd, Lansing, Sussex). Cuff size was determined by arm circumference. Two sitting blood pressure measurements, taken 1-minute apart, were averaged to obtain the systolic and diastolic BP. Blood pressure was categorized as normal, pre-hypertension, hypertension stage I, and hypertension stage II using the Joint National Committee on Prevention, Detection, Evaluation, and Treatment of High Blood Pressure Seventh Report (JNC7) blood pressure classifications [73]. Hypertension status in the JHS database is defined as blood pressure $\geq 140 / 90 \mathrm{mmHg}$ and use of blood pressure lowering medication (actual or self reported) within 2 weeks prior to clinic visit [73]. The JHS also classified hypertensive participants according to whether or not they were treated or controlled. Treatment was defined as taking 1 of 7 classes of antihypertensive medication. A blood pressure $<$ 140/90 mm Hg while being treated was defined as control [5].

Coping style was the independent variable in this study. Coping style was measured using the Coping Strategies Inventory Short Form (CSI-SF), a four-factor 15item instrument developed to measure coping responses in the JHS cohort. Each participant was given the 15-item CSI-SF at the conclusion of the home induction interview (HII) as part of the Approach to Life booklet in the Bring to Clinic section [70] and instructed to complete and return the form at the next clinic visit.

The CSI-SF has a two-level subscale format. The first level consists of two major scales - engagement and disengagement, and the second level consists of the following 
four subscales: problem-focused engagement (PFE), problem-focused disengagement (PFD), emotion-focused engagement (EFE) and emotion-focused disengagement (EFD) [18]. Each item was evaluated using a 5-point Likert Scale that ranged from 1 (never), 2 (seldom), 3 (sometimes), 4 (often), and 5 (almost always). Scoring consisted of summarized responses to items contained in each subscale with minimum scores ranging from 4 to 20 in minor scales and 8 to 40 in major scales [70] (Appendix C).

Demographic characteristics such as education, employment, and income status were collected at baseline on all JHS participants. Educational categories were defined as: less than high school; high school; some or completed vocational or some college; associate degree; college degree, and post-college. The income levels were poor, lowermiddle, middle-upper, and affluent [75]. Other co-variates included cardiovascular risk factors such as alcohol consumption, tobacco use, physical activity, and BMI, which have been shown to influence blood pressure.

The Physical Activity 30 item questionnaire assessed whether or not the participants lead active or sedentary lifestyles. Participants were asked to respond to a combination of yes/no and 5-point Likert-type questions [74]. The Health Practices: Tobacco Use tool assessed environmental tobacco smoke exposure and nicotine dependence for participants who smoked cigarettes in the JHS. The form included 29 questions related to cigarettes, pipes, cigars, chewing tobacco, and dip/snuff [74]. In this study, cigarette smoking categories such as never smoked, former smoker, and current smoking were assessed (Appendix D). The JHS used the Health Practices: Alcohol and Drug Use form to measure alcohol and drug use, The ADRA consist of five alcohol consumption-related items and three drug-use items. The 8-item instrument consists of a combination of yes/no, fill-in the blank and Likert-type questions. This study measured alcohol drinking in the past 12 months and number of drinks per week (Appendix E). Body mass index (BMI) was calculated as weight $(\mathrm{kg})$ divided by height squared $\left(\mathrm{m}^{2}\right)$ to measure normal, overweight and obesity in the current study.

\section{Statistical Analysis}

Descriptive statistics were generated to describe the sample and the distribution of the dependent, independent, and covariates. All analyses were conducted using Statistical Package for the Social Sciences (SPSS software version 18.0) [77]. The dependent variables in the current study were SBP, DBP, normotension and hypertension. The independent variable was gender; the mediator independent variables were problemfocused and emotion-focused engagement, problem-focused- and emotion-focused disengagement; total engagement and total disengagement coping; and the moderator independent variables were age, income, education, BMI, alcohol consumption, tobacco use and physical activity. For aim one, means and standard deviations were generated for the total CSF scale as well as for each subscale. For aim two, Pearson's product-moment correlation coefficient analysis was computed to assess the relationships between coping style and blood pressure and independent sample t-tests were generated to identify gender

differences in coping style and linear regression models were generated to determine 
whether age, education, income, BMI, alcohol consumption and tobacco use act as moderators for gender differences in coping style in JHS men and women. For aim three, stepwise multiple regressions (both linear and logistic) were used to determine the associations among engagement, disengagement, problem- and emotion-focused engagement, problem- and emotion-focused disengagement, SBP, DBP, normotension, and hypertension while controlling for the covariates [76]. These data were used to describe the sample and were included in the regression models as co-variates. To test for mediation, Sobel mediation analysis was conducted. All inferential statistics were performed at a significance level of 0.05 .

\section{Specific Aims}

Aim One: To Characterize the Coping Style Used by African Americans

Means and standard deviations were generated for the total CSF scale as well as for each subscale.

Aim Two: To Assess Gender Differences in Coping Styles of African Americans

Pearson's product-moment correlation coefficient analysis was computed to assess the relationships between coping style and blood pressure, and independent sample t-tests were generated to identify gender differences in coping style. Linear regression models were generated to determine whether age, SES, BMI, alcohol consumption, and tobacco use act as moderators for gender differences in coping style.

Aim Three: To Determine the Relationship between Coping Style and Hypertension in African Americans

Logistic regression analyses were used to determine the associations among engagement, disengagement, problem- and emotion-focused engagement, problem- and emotion-focused disengagement and hypertension status.

\section{Study Results}

\section{Description of Demographic Characteristics}

Forty-three hundred and fifty four men $(n=1,557)$ and women $(n=2,797)$ met the inclusion criteria and were included in this study. The sample consisted of $64 \%$ women and 35.8\% men. Descriptive statistics for the demographic variables are listed in Table 4-1. The age category 55-64, had the highest percentage (27.8) followed by $24.9 \%$ 
Table 4-1. Description of Sample Demographic Characteristics

\begin{tabular}{|c|c|c|c|}
\hline Variable & $\begin{array}{c}\text { Total } \\
N=4354\end{array}$ & $\begin{array}{c}\text { Men } \\
\mathbf{N}=\mathbf{1 5 5 7} \\
\mathbf{( 3 5 . 8 \% )}\end{array}$ & $\begin{array}{r}\text { Women } \\
\text { N = 2797 } \\
(64.2 \%)\end{array}$ \\
\hline \multicolumn{4}{|l|}{ Age } \\
\hline $21-34$ & $192(4.4)$ & $73(4.7)$ & $119(4.3)$ \\
\hline $35-44$ & $847(19.5)$ & $326(20.9)$ & $521(18.6)$ \\
\hline $45-54$ & $1085(24.9)$ & $396(25.4)$ & $689(24.6)$ \\
\hline $55-64$ & $1212(27.8)$ & $418(26.8)$ & $794(28.4)$ \\
\hline $65-74$ & $802(18.4)$ & $272(17.5)$ & $530(18.9)$ \\
\hline $75-84$ & $207(4.8)$ & $67(4.3)$ & $140(5)$ \\
\hline Over 85 & $9(0.2)$ & $5(0.3)$ & $4(0.1)$ \\
\hline \multicolumn{4}{|l|}{ Education } \\
\hline$<$ High School & $718(16.5)$ & $273(17.6)$ & $445(15.9)$ \\
\hline $\begin{array}{l}\text { High School/ } \\
\text { GED or Some College }\end{array}$ & $1825(42.1)$ & $655(42.3)$ & $1170(41.9)$ \\
\hline $\begin{array}{l}\text { College/Associate Degree } \\
\text { or Higher }\end{array}$ & $1797(41.1)$ & $622(40.1)$ & $1175(42.1)$ \\
\hline \multicolumn{4}{|l|}{ Income } \\
\hline Low & $538(14.5)$ & $131(9.9)$ & $407(17.1)$ \\
\hline Lower-Middle & $916(24.8)$ & $283(21.4)$ & $633(26.7)$ \\
\hline Upper-Middle & $1116(30.2)$ & $397(30.0)$ & $719(30.3)$ \\
\hline Affluent & $1129(30.5)$ & $514(38.8)$ & $615(25.9)$ \\
\hline
\end{tabular}


for the age category $45-54$. Over $42 \%$ of the participants had high school level education and at least some college and almost $25 \%$ had lower to middle incomes. Then again, over $30 \%$ of the sample reported upper-middle to affluent lifestyles. In spite of this, findings showed significant gendered-differences in lifestyle, such as $17.1 \%$ of the women reported having low incomes compared to men (9.9\%). At least $42.1 \%$ of the women graduated with associate degrees compared to men (40.1\%). Another significant gender difference is that more men reported affluent income status $(38.8 \%)$ compared to $25.9 \%$ of the women in the same category.

\section{Description of Sample Cardiovascular Risk Characteristics}

Table 4-2 displays the cardiovascular risk characteristics of the sample. Fifty-four percent of the sample reported not drinking alcohol in the past 12 months. Even more important was the fact that $68.4 \%$ of the participants had never smoked. An astonishing number of participants (53\%) were obese, with BMI levels greater than $30 \mathrm{~kg} / \mathrm{m}^{2}$. Furthermore, $32.6 \%$ reported being overweight and had BMIs between $25-30 \mathrm{~kg} / \mathrm{m}^{2}$. More women reported drinking alcohol in the past 12 months $(61.1 \%)$ than men $(41.3 \%)$. Regarding smoking status, $74.4 \%$ of the women and $57.5 \%$ of the men had never smoked. However, more men were current smokers (16.9\%) compared to only $10.0 \%$ of women participants. Also noted was that $60 \%$ of the women had a BMI greater than 30 $\mathrm{kg} / \mathrm{m}^{2}$ compared to $40.7 \%$ of the men with the same BMI.

\section{Description of Sample Blood Pressure Characteristics}

Table 4-3 describes blood pressure status characteristics of the sample. In general, $53.2 \%$ of the sample was treated with anti-hypertension medication. Only $28.5 \%$ had normal BP according to the JNC7 BP classification. Noted gender differences included $31.5 \%$ of the women had normal BP compared to men $(23.0 \%)$, and within each group, both men (44.3\%) and women (43.7\%) fell within the pre-hypertension stage. Nevertheless, $24.3 \%$ of men had stage I hypertension compared to women $(19.1 \%)$. Remarkably, $60 \%$ or more in both groups had been treated with antihypertensive medication for blood pressures $>140 / 90$ per JNC7 [73]. Also, Table 4-3 indicates women were slightly older $(53.40 \pm 11.0)$ compared to men $(53.10 \pm 10.09)$. Men averaged 127.22 (SD 16.7) for SBP and had an average DBP of 81.63 (SD 10.5). Comparatively, the average SBP for women was 125.91 (SD 18.0) and the average DBP for women was 77.46 (SD 10.0) by JNC7 classifications [73].

\section{Aim One: Coping Styles Used by African Americans}

Table 4-4 displays the mean scores and standard deviations for the two major and four minor coping scales. Coping style mean score comparisons showed that JHS participants used engagement coping styles [TFE (28.17 \pm 4.5$)$, PFE (15.10 \pm 2.6$)$, and EFE $(13.07 \pm 2.9)]$ more than disengagement coping styles [PFD $(11.58 \pm 2.9)$, EFD 
Table 4-2. Description of Sample Cardiovascular Risk Characteristics

\begin{tabular}{|c|c|c|c|c|}
\hline \multicolumn{2}{|l|}{ Variable } & $\begin{array}{c}\text { Total } \\
(\mathrm{N}=4354) \\
\mathrm{n}(\%)\end{array}$ & $\begin{array}{c}\text { Men } \\
(\mathrm{n}=1557) \\
\mathrm{n}(\%)\end{array}$ & $\begin{array}{c}\text { Women } \\
(\mathrm{n}=\mathbf{2 7 9 7 )} \\
\mathrm{n}(\%) \\
\end{array}$ \\
\hline \multicolumn{5}{|c|}{$\begin{array}{l}\text { Alcohol Drinking in the } \\
\text { Past } 12 \text { Months }(\mathrm{Y} / \mathrm{N})\end{array}$} \\
\hline \multicolumn{2}{|c|}{ Yes } & $2342(54.0)$ & $640(41.3)$ & $1702(61.1)$ \\
\hline \multicolumn{2}{|l|}{ No } & $1993(46.0)$ & $910(58.7)$ & $1083(38.9)$ \\
\hline \multicolumn{5}{|c|}{ Smoking Status } \\
\hline \multicolumn{2}{|c|}{ Never Smoked } & $2959(68.4)$ & $890(57.59)$ & $2069(74.4)$ \\
\hline \multicolumn{2}{|c|}{ Former Smoker } & $830(19.2)$ & $397(25.6)$ & $433(15.6)$ \\
\hline \multicolumn{2}{|c|}{ Current Smoker } & $540(12.5)$ & $261(16.9)$ & $279(10.0)$ \\
\hline \multicolumn{5}{|c|}{ BMI $\left(\mathrm{kg} / \mathrm{m}^{2}\right)$} \\
\hline Normal & $<25$ & $624(14.4)$ & $290(18.6)$ & $334(12.0)$ \\
\hline Overweight & $25-30$ & $1415(32.6)$ & $632(40.6)$ & $783(28.0)$ \\
\hline Obese & $\geq 30$ & $2308(53.1)$ & $633(40.7)$ & $1675(60.0)$ \\
\hline
\end{tabular}

Note: $\mathrm{BMI}=$ Body Mass Index. 
Table 4-3. Description of Sample Blood Pressure and Hypertension Characteristics

\begin{tabular}{|c|c|c|c|}
\hline Variable & $\begin{array}{c}\text { Total } \\
(\mathbf{N}=4354) \\
\mathbf{N}(\%) \\
\text { Mean/SD } \\
\end{array}$ & $\begin{array}{c}\text { Men } \\
(n=1557) \\
n(\%) \\
\text { Mean } / \text { SD } \\
\end{array}$ & $\begin{array}{c}\text { Women } \\
(n=2792) \\
n(\%) \\
\text { Mean } / \text { SD } \\
\end{array}$ \\
\hline \multicolumn{4}{|l|}{ Classifications } \\
\hline Normal & $1236(28.5)$ & $357(23.0)$ & $879(31.5)$ \\
\hline Pre-Hypertension & $1906(43.9)$ & $688(44.3)$ & $1218(43.7)$ \\
\hline Hypertension Stage I & $911(21.9)$ & $378(24.3)$ & $533(19.1)$ \\
\hline Hypertension Stage II & $290(6.7)$ & $131(8.4)$ & $159(5.7)$ \\
\hline \multicolumn{4}{|l|}{ Normotension } \\
\hline $\begin{array}{l}\text { BP }<140 / 90 \text { and No History of } \\
\text { Taking BP Medication }\end{array}$ & $1603(37.1)$ & $614(39.8)$ & $989(35.6)$ \\
\hline \multicolumn{4}{|l|}{ Hypertension } \\
\hline $\begin{array}{l}\mathrm{BP} \geq 140 / 90 \mathrm{~mm} \text { hg or History of } \\
\text { Taking BP Medication }\end{array}$ & $2718(62.9)$ & $930(60.2)$ & $1788(64.4)$ \\
\hline Age & $54.68 \pm 12.5$ & $53.10 \pm 10.9$ & $53.40 \pm 11.0$ \\
\hline SBP & $\begin{array}{c}126.75 \pm \\
18.2\end{array}$ & $\begin{array}{c}127.22 \pm \\
16.7\end{array}$ & $\begin{array}{c}125.91 \pm \\
18.0\end{array}$ \\
\hline DBP & $78.84 \pm 10.5$ & $81.63 \pm 10.5$ & $77.46 \pm 10.0$ \\
\hline BMI & $31.75 \pm 7.2$ & $29.03 \pm 6.2$ & $32.44 \pm 7.5$ \\
\hline Physical Activity & $8.39 \pm 2.5$ & $8.70 \pm 2.59$ & $8.22 \pm 2.54$ \\
\hline
\end{tabular}

Note: $\mathrm{SBP}=$ Systolic Blood Pressure, DBP $=$ Diastolic Blood Pressure, BMI = Body Mass Index. 
Table 4-4. Means and Standard Deviations of Coping Style Scores $(\mathrm{N}=4354)$

\begin{tabular}{lc}
\hline Coping Styles & Total Cohort \\
\hline Problem-Focused Engagement & $15.10 \pm 2.6$ \\
Problem-Focused Disengagement & $11.58 \pm 2.9$ \\
Emotion-Focused Engagement & $13.07 \pm 2.9$ \\
Emotion-Focused Disengagement & $8.37 \pm 2.1$ \\
Engagement Coping & $28.17 \pm 4.5$ \\
Disengagement Coping & $19.93 \pm 4.0$ \\
\hline
\end{tabular}


$(8.37 \pm 2.1)$, and TFD $(19.93 \pm 4.02)]$. Seventy-five percent of the PFE scores were under 17.00 , and $75 \%$ of EFE scores were below 15.00 . Comparatively, $75 \%$ of PFD scores fell below 13.00 and EFD fell below 10.00. The distribution of scores for each coping style is displayed in Figure 4-1 to Figure 4-4.

Aim Two: Gender Differences in Coping Styles Used by African Americans

Independent-sample t tests were conducted to compare differences in JHS men's and women's coping scores. Table 4-5 shows that for different coping styles, the mean coping levels for men and women are significantly different. Findings for men and women, respectively, showed that women had slightly higher scores on most subscales [PFD (11 \pm 3 vs. $12 \pm 3)$; EFE (12 \pm 3 vs. $13 \pm 3)$; EFD ( $8 \pm 2$ vs. $9 \pm 2)$ ]. On the other hand, men $(15.39 \pm 2.66)$ had significantly higher scores than women $(14.93 \pm 2.61)$ on PFE. Analysis of coping styles by gender (Figure 4-1) showed that 250 out of 1,509 men (16.6\%) scored 16 out of 20 on PFE. More women (Figure 4-2) had higher PFD scores $(16.7 \%)$ compared to men on the same scale $(14.4 \%)$. Both men $(17.9 \%)$ and women (15.7\%) scored 12 out of 20 on EFE (Figure 4-3) and both groups (Figure 4-4) scored 9 out of 20 on EFD (men $21.6 \%$ and women $21.3 \%$ ).

Aim Three: Relationship between Coping Style and Blood Pressure in African Americans

PFD was significantly correlated with systolic blood pressure in women, correlation coefficient $0.065, \mathrm{n}=2,668, \mathrm{p}=.001$ as well as in the total cohort, SBP $[\mathrm{r}=$ $0.04, \mathrm{n}=4,174, \mathrm{p}=.007$ ] (Table 4-6). There was a negative correlation between EFE and DBP $[\mathrm{r}=-0.041, \mathrm{n}=4204, \mathrm{p}=.007]$ in the total sample. Comparatively, results indicated that EFD was negatively correlated with SBP $[r=-0.032, n=4201, p=.040]$. Overall, significant correlations were found between PFD and SBP for women. Negative correlations were found between EFE and DBP and between EFD and SBP. However, no correlations were found between coping style and BP in men. Although some of the correlation coefficients are statistically significantly different from zero, they are not practically significant.

\section{Regression Analysis}

In Table 4-7 positive relationships were found between SBP and gender ( $\beta=$ $.079, \mathrm{p}<.001)$; smoking $(\beta=.053, \mathrm{p}=.003)$; and BMI $(\beta=.067, \mathrm{p}<.001)$. Negative relationships were found with SBP and education $(\beta=-.060, p=.005)$; alcohol consumption $(\beta=-.090, p<.001)$; and physical activity $(\beta=-.103, p<.001)$. There were no positive or negative relationships with SBP and coping styles. The analysis indicated that as BMI and smoking status increases, so does SBP. Comparatively, as alcohol consumption, physical activity, and educational status increases, SBP decreases and vice versa. There were no negative or positive relationships with coping styles and DBP, as indicated in Table 4-8. Nevertheless, regression analysis showed positive relationships 


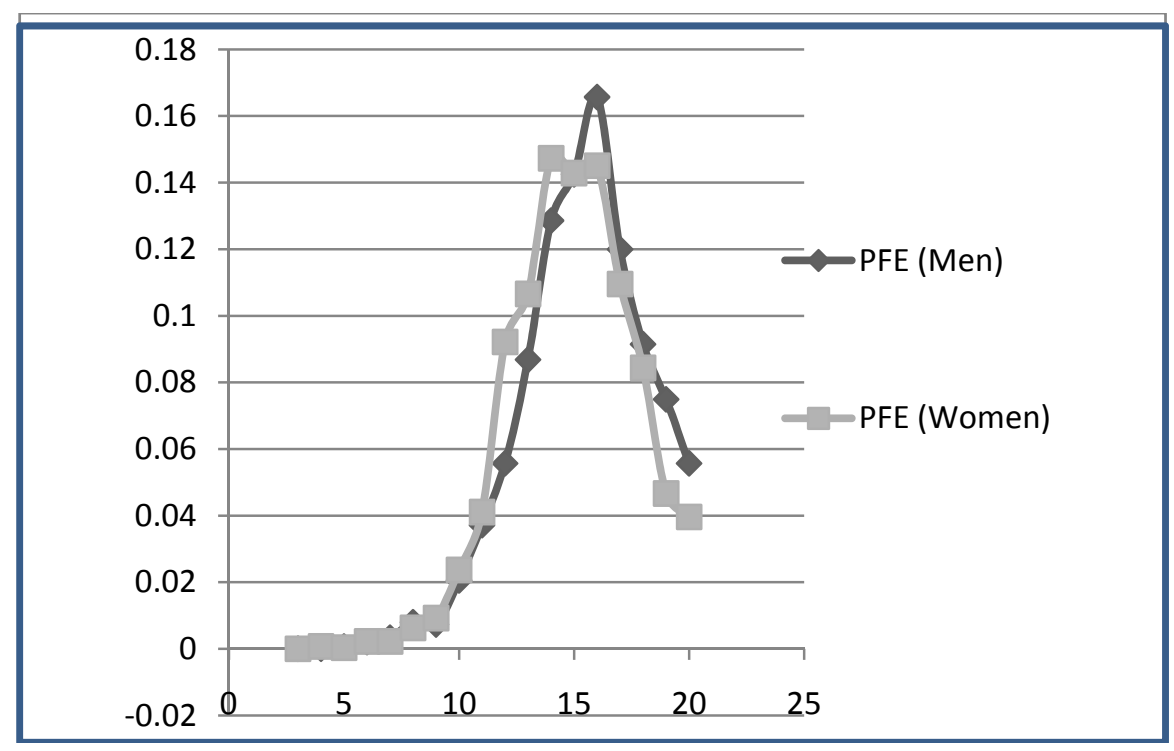

Figure 4-1. Distribution of PFE Scores

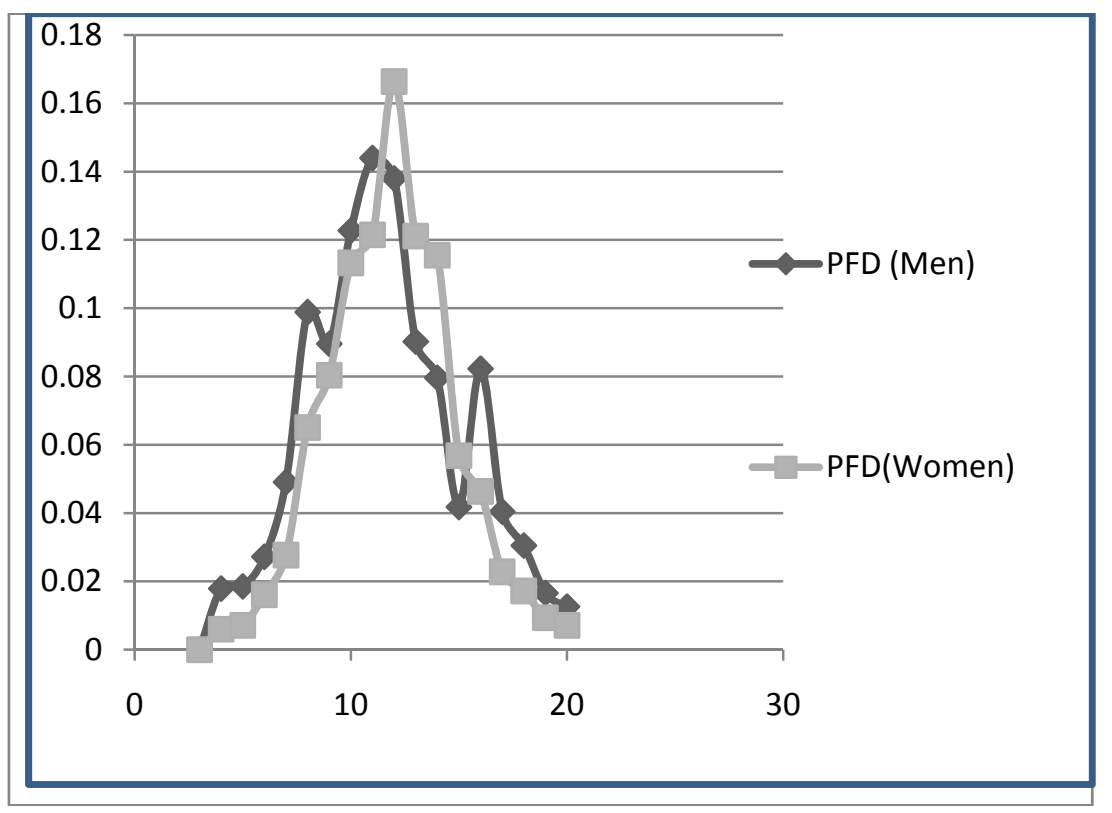

Figure 4-2. Distribution of PFD Scores 


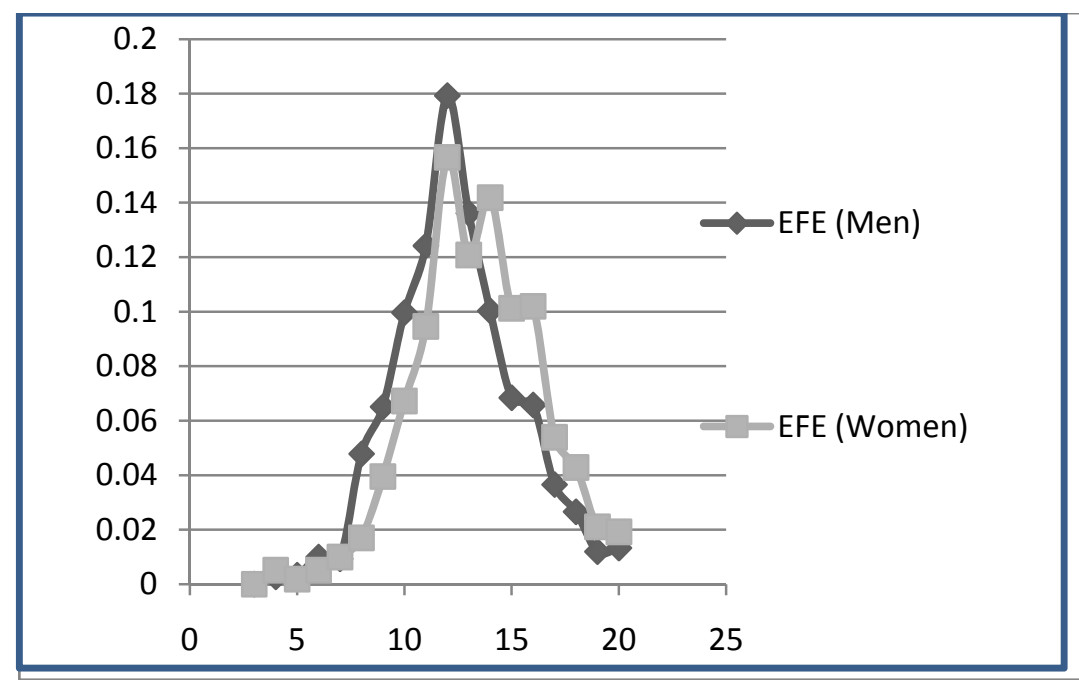

Figure 4-3. Distribution of EFE Scores

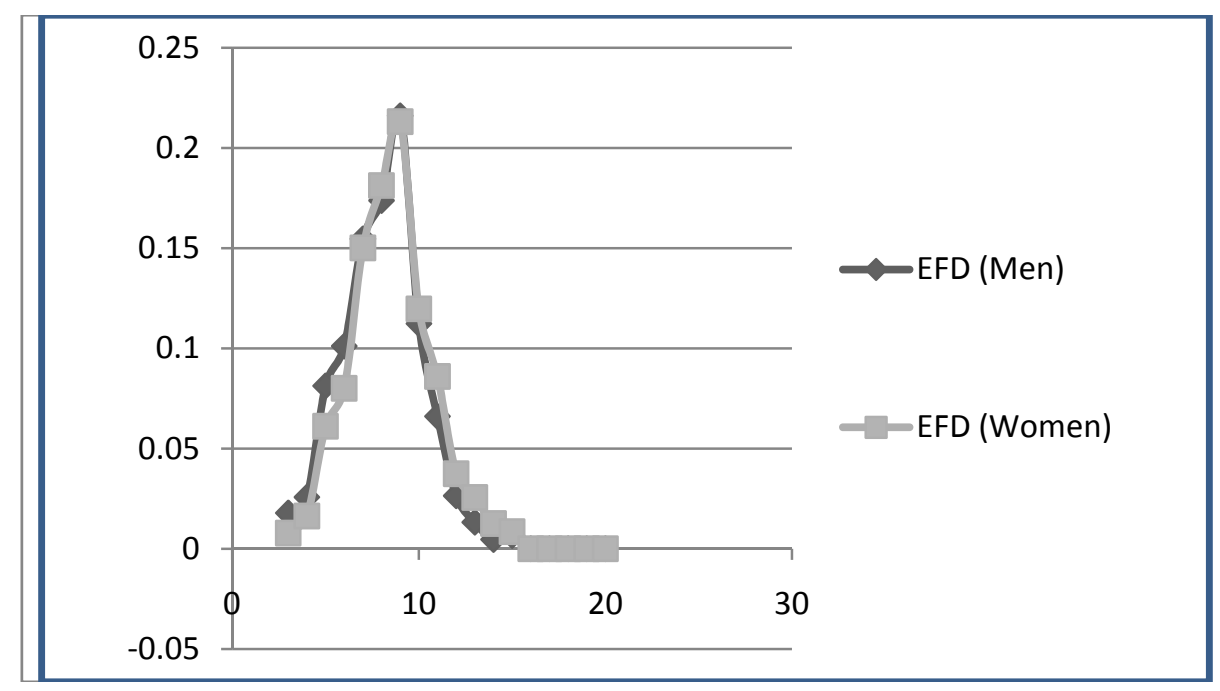

Figure 4-4. Distribution of EFD Scores 
Table 4-5. Coping Style Significance Results

\begin{tabular}{lccc}
\hline Coping Styles & Men & Women & P Value \\
\hline Problem-Focused Engagement & $15.39 \pm 2.66$ & $14.93 \pm 2.61$ & $\mathrm{p}<.0001$ \\
Problem-Focused Disengagement & $11.07 \pm 3.09$ & $11.87 \pm 2.87$ & $\mathrm{p}<.0001$ \\
Emotion-Focused Engagement & $12.48 \pm 2.84$ & $13.39 \pm 2.88$ & $\mathrm{p}<.0001$ \\
Emotion-Focused Disengagement & $8.09 \pm 2.15$ & $8.53 \pm 2.18$ & $\mathrm{p}<.0001$ \\
Total Engagement & $27.87 \pm 4.5$ & $28.34 \pm 4.57$ & $\mathrm{p}=.002$ \\
Total Disengagement & $19.16 \pm 4.09$ & $20.36 \pm 3.91$ & $\mathrm{p}<.0001$ \\
\hline
\end{tabular}

Table 4-6. Correlations between Coping and Blood Pressure

\begin{tabular}{|c|c|c|c|c|c|c|}
\hline \multirow[b]{2}{*}{ Coping Style } & \multicolumn{3}{|c|}{ DBP } & \multicolumn{3}{|c|}{ SBP } \\
\hline & Men & Women & Total & Men & Women & Total \\
\hline Problem-Focused Engagement & -.011 & .010 & .006 & -.007 & -.034 & -.007 \\
\hline Problem-Focused Disengagement & .020 & $.065^{* *}$ & $.042^{* *}$ & -.037 & .023 & -.025 \\
\hline Emotion-Focused Engagement & .015 & -.015 & -.011 & .007 & -.025 & $-.041^{* *}$ \\
\hline Emotion-Focused Disengagement & -.039 & -.022 & $-032^{*}$ & .010 & .027 & .002 \\
\hline Total Focused Engagement & .006 & -.003 & -.002 & .001 & -.033 & -.029 \\
\hline Total Focused Disengagement & -.006 & .032 & .012 & -.023 & .033 & -.017 \\
\hline
\end{tabular}

Note: $* *$ Correlation is significant at the 0.01 level (2-tailed). ${ }^{*}$ Correlation is significant at the 0.05 level (2-tailed). DBP $=$ Diastolic Blood Pressure; SBP $=$ Systolic Blood Pressure. 
Table 4-7. Linear Regression of Systolic Blood Pressure on Gender and Coping Styles

\begin{tabular}{lcc}
\hline Standardized Coefficients $^{\mathbf{a}}$ & $\begin{array}{c}\text { Beta } \\
(\boldsymbol{\beta})\end{array}$ & $\begin{array}{c}\mathbf{P} \\
\text { Value }\end{array}$ \\
\hline (Constant) & .000 \\
Gender & .079 & .000 \\
Problem-Focused Engagement & .006 & .846 \\
Problem-Focused Disengagement & .021 & .244 \\
Emotion-Focused Disengagement & -.030 & .099 \\
Total Focused Engagement & .011 & .722 \\
Education Level & -.060 & .005 \\
Income Status & -.001 & .960 \\
Smoking Status & .053 & .003 \\
Alcohol Consumption & -.090 & .000 \\
Physical Activity & -.103 & .000 \\
Body Mass Index & .067 & .000 \\
\hline
\end{tabular}

Note: ${ }^{\mathrm{a} D e p e n d e n t ~ v a r i a b l e: ~ S y s t o l i c ~(c o m p u t e d ~ n e t ~ a v e r a g e) . ~}$ 
Table 4-8. Linear Regression of Diastolic Blood Pressure on Gender and Coping Styles

\begin{tabular}{lcc}
\hline Standardized Coefficients $^{\mathbf{a}}$ & Beta $(\boldsymbol{\beta})$ & P Value \\
\hline (Constant) & .211 & .000 \\
Gender & -.043 & .000 \\
Problem-Focused Engagement & .018 & .150 \\
Problem-Focused Disengagement & .323 \\
Emotion-Focused Disengagement & .001 & .960 \\
Total Focused Engagement & .014 & .639 \\
Education Level & .005 & .820 \\
Income Status & .027 & .195 \\
Smoking Status & -.006 & .753 \\
Alcohol Consumption & -.019 & .292 \\
Physical Activity & .081 & .000 \\
Body Mass Index & .073 & .000 \\
\hline
\end{tabular}

Note: ${ }^{a}$ Dependent variable: Diastolic (computed net average). 
among DBP and gender $(\beta=.211, \mathrm{p}<.001)$, physical activity $(\beta=.081, \mathrm{p}<.001)$, BMI $(\beta=.073, \mathrm{p}<.001)$, and smoking $(\mathrm{p}<.001)$. Physical activity $(\mathrm{p}<.05)$ and BMI $(\mathrm{p}<$ $.05)$ had more impact in the regression model than the other predictor variables. Predictor variables gender and BMI had the most impact in the regression and were more statistically significant than the others.

Multiple logistic regression analysis (Table 4-9) showed highly significant relationships between age $(\beta=.080, \mathrm{p}<.001)$ and BMI $(\beta=.065, \mathrm{p}<.001)$, which indicates that as age and BMI increase, the risk for high BP increases. Findings showed that participants who have a Bachelor degree $(\beta=.400, p<.05)$ are more likely to have higher BP. Individuals with lower-middle $(\beta=.329, \mathrm{p}<.05)$, upper-middle $(\beta=.257, \mathrm{p}<$ $.05)$, and affluent $(\beta=.234, \mathrm{p}<.05)$ incomes are more at risk for high BP than individual with low incomes. The positive significant relationship for alcohol consumption $(\beta=$ $.197, \mathrm{p}<.05)$ indicates that people who consume alcohol are more likely to have higher BP than people who do not. Of the coping styles, only PFE $(\beta=-.036$, OR $=.964, p<.05)$ and $\mathrm{EFE}(\beta=.037, \mathrm{OR}=1.038, \mathrm{p}<.05)$ were found to be significant. Participants with high EFE scores are more likely to have higher BP than participants who do not. Comparatively, if PFE scores are high, then there is less risk for high BP because PFE negatively affects BP. Increased physical activity scores $(\beta=-.014, \mathrm{OR}=.986)$ result in decreased risk for high BP. Gender, PFD, and EFD were not significantly related to BP, and neither was smoking.

\section{Results of Mediation Analysis}

Using systolic blood pressure as the measure for blood pressure, based on the Sobel Test for mediation, we noted that the coping minor subscales PFD $(\mathrm{t}=74.9180, \mathrm{p}=$ $0.0071)$ and EFD $(t=1.9642, p=0.0495)$ both mediate the relation between gender and systolic blood pressure. There were two minor subscales; also, two major subscales were not significant mediators of systolic blood pressure. However, for diastolic blood pressure, only the minor subscale EFE $(\mathrm{t}=2.5707, \mathrm{p}=0.0102)$ significantly mediated the relation of gender and diastolic blood pressure. See Table 4-10 and Figure 4-5 and Figure 4- 6 for details. 
Table 4-9. Multiple Logistic Regression of Blood Pressure on Gender, Age, Income, Education, Smoking, Alcohol, Physical Activity, BMI, and Coping Styles

\begin{tabular}{|c|c|c|c|c|c|c|}
\hline \multirow[t]{2}{*}{ Variable $^{\mathrm{a}}$} & \multirow{2}{*}{$\begin{array}{c}\text { Beta } \\
(\beta)\end{array}$} & \multirow{2}{*}{$\begin{array}{c}\text { Standard } \\
\text { Error }\end{array}$} & \multirow{2}{*}{$\begin{array}{c}P \\
\text { Value }\end{array}$} & \multirow[t]{2}{*}{$\mathbf{O R}$} & \multicolumn{2}{|c|}{ 95.0\% C.I. } \\
\hline & & & & & Lower & Upper \\
\hline Age & .080 & .004 & .000 & 1.083 & 1.074 & 1.093 \\
\hline Gender & -.173 & .093 & .063 & .842 & .702 & 1.009 \\
\hline BMI & .065 & .006 & .000 & 1.067 & 1.054 & 1.080 \\
\hline \multicolumn{7}{|l|}{ Coping Style } \\
\hline PFE & -.036 & .018 & .040 & .964 & .932 & .998 \\
\hline PFD & -.002 & .015 & .899 & .998 & .970 & 1.027 \\
\hline EFE & .037 & .015 & .016 & 1.038 & 1.007 & 1.069 \\
\hline EFD & -.019 & .020 & .342 & .981 & .943 & 1.021 \\
\hline \multicolumn{7}{|l|}{ Education } \\
\hline$<$ High School & & & .280 & & & \\
\hline High & .080 & .179 & .657 & 1.083 & .762 & 1.540 \\
\hline \multicolumn{7}{|l|}{ School/GED } \\
\hline Some College & .186 & .150 & .215 & 1.204 & .898 & 1.615 \\
\hline Associate & .091 & .137 & .506 & 1.096 & .837 & 1.434 \\
\hline \multicolumn{7}{|l|}{ Degree } \\
\hline Bachelor & .400 & .179 & .026 & 1.491 & 1.050 & 2.119 \\
\hline Degree & & & & & & \\
\hline Post College & .201 & .135 & .138 & 1.222 & .938 & 1.593 \\
\hline \multicolumn{7}{|l|}{ Smoking } \\
\hline Never & & & .087 & & & \\
\hline Former & -.216 & .128 & .091 & .806 & .628 & 1.035 \\
\hline Current & -.017 & .152 & .912 & .983 & .731 & 1.324 \\
\hline \multicolumn{7}{|l|}{ Income } \\
\hline Low & & & .074 & & & \\
\hline Lower-Middle & .329 & .155 & .034 & 1.389 & 1.025 & 1.883 \\
\hline Upper-Middle & .257 & .127 & .042 & 1.293 & 1.009 & 1.657 \\
\hline Affluent & .234 & .107 & .028 & 1.264 & 1.025 & 1.559 \\
\hline \multicolumn{7}{|l|}{ Alcohol } \\
\hline Yes & .197 & .088 & .025 & 1.218 & 1.025 & 1.446 \\
\hline Physical & -.014 & .018 & .443 & .986 & .952 & 1.022 \\
\hline \multicolumn{7}{|l|}{ Activity } \\
\hline Constant & -5.615 & .546 & .000 & .004 & & \\
\hline
\end{tabular}

Note: ${ }^{a}$ Variable(s) entered on step 1: AGE01, GENDER, BMI01, PFE01, PFD01, EFE01, and $\mathrm{EFD} . \mathrm{OR}=$ Odds Ratio, $\mathrm{CI}=$ Confidence Interval, $\mathrm{BMI}=$ Body Mass Index. 
Table 4-10. Sobel Test of Mediation on the Relationship between Gender and Blood Pressure

\begin{tabular}{lccccccccc}
\hline $\begin{array}{l}\text { Dependent } \\
\text { Variable }\end{array}$ & $\begin{array}{c}\text { Mediation } \\
\text { Factors }\end{array}$ & $\mathbf{a}$ & $\mathbf{s}_{\mathbf{a}}$ & $\mathbf{b}$ & $\mathbf{s}_{\mathbf{b}}$ & $\mathbf{c}$ & $\mathbf{s}_{\mathbf{c}}$ & $\begin{array}{c}\text { Sobel } \\
\text { Test }\end{array}$ & $\begin{array}{c}\text { P } \\
\text { Value }\end{array}$ \\
\hline Systolic BP & PFD & -0.797 & 0.095 & 0.253 & 0.094 & 1.636 & 0.574 & 74.918 & 0.0071 \\
& PFE & 0.454 & 0.085 & 0.044 & 0.106 & 1.636 & 0.574 & 0.0483 & 0.679 \\
& EFE & -0.917 & 0.092 & -0.066 & 0.096 & 1.636 & 0.574 & 0.6859 & 0.4928 \\
& EFD & -0.434 & 0.070 & -0.263 & 0.127 & 1.636 & 0.574 & 1.9642 & 0.0495 \\
& TD & -1.204 & 0.129 & 0.053 & 0.070 & 1.636 & 0.574 & -0.7547 & 0.4505 \\
& TE & -0.467 & 0.147 & -0.008 & 0.061 & 1.636 & 0.574 & 0.1310 & 0.8957 \\
Diastolic BP & & & & & & & & & \\
& PFD & -0.797 & 0.095 & -0.089 & 0.054 & 4.191 & 0.326 & 1.6172 & 0.1058 \\
& PFE & 0.454 & 0.085 & -0.029 & 0.061 & 4.191 & 0.326 & -0.4735 & 0.6358 \\
& EFE & -0.917 & 0.092 & -0.149 & 0.056 & 4.191 & 0.326 & 2.5707 & 0.0102 \\
& EFD & -0.434 & 0.070 & 0.009 & 0.074 & 4.191 & 0.326 & -0.1216 & 0.9032 \\
& TD & -1.204 & 0.129 & -0.044 & 0.041 & 4.191 & 0.326 & 1.0661 & 0.2864 \\
& TE & -0.467 & 0.147 & -0.067 & 0.036 & 4.191 & 0.326 & 1.6058 & 0.1083 \\
\hline
\end{tabular}

Note: PFD = Problem-Focused Disengagement, PFE = Problem-Focused Engagement, EFE = Emotion-Focused

Engagement, $\mathrm{EFD}=$ Emotion-Focused Disengagement, $\mathrm{TE}=$ Total Engagement, $\mathrm{TD}=$ Total Disengagement 


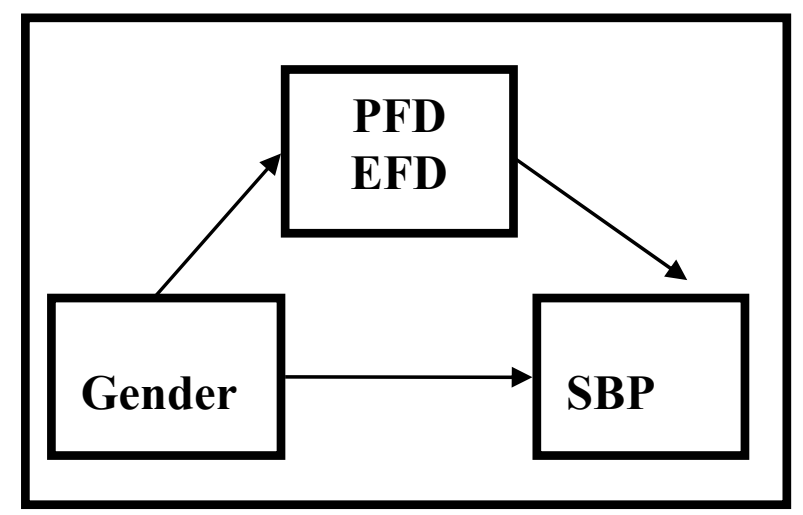

Figure 4-5. The Effects of Problem-Focused Disengagement and Emotion-Focused Disengagement on Systolic Blood Pressure

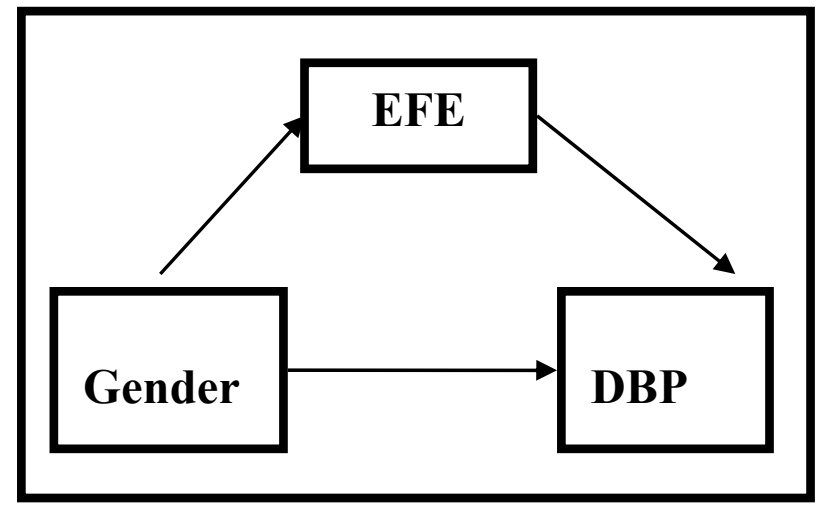

Figure 4-6. The Effects of Emotion-Focused Engagement on Diastolic Blood Pressure 


\section{CHAPTER 5. DISCUSSION}

In our cohort of 4,354 JHS men and women, we found that the primary coping style was problem-focused engagement. We also found that emotion-focused engagement styles significantly mediate the relationship between gender and diastolic blood pressure. We also found that both problem-focused and emotion-focused disengagement coping styles mediate the relationship between gender and systolic blood pressure.

Coping styles can directly impact the emotional and physical consequences of stressful live events [26]. The two primary coping styles are engagement and disengagement. Engagement is sometimes described as an approach or active coping style, and disengagement is sometimes described as avoidant or passive coping $[39,40]$. In the JHS cohort, engagement and disengagement coping were measured using the Coping Strategies Inventory Short Form (CSI-SF) for 4,354 participants [18].

A significant negative correlation between diastolic blood pressure and emotionfocused coping was found in our study, indicating that when JHS participants use EFE styles, DBP decreases. Emotion-focused engagement coping (EFE) involves seeking the advice of family, friends, and clergy for emotional, economic, and social support during stressful events. An emotion-focused engagement (EFE) style was found to be used frequently by African Americans participating in a study that examined racism, chronic stress emotions, and blood pressure. The sample consisted of 162 adult African American men $(n=29)$ and women $(n=133)$ from 18 to 80 years old. Findings showed that $18 \%$ used EFE and 47\% did not [6].

In this study, we found that alcohol impacted DBP. Russell and colleagues found a significant relationship between changes in alcohol use and blood pressure. Findings also showed that alcohol use predicted avoidance coping during stressful events in men and women [34]. Emotion-focused disengagement (EFD) coping or avoidance coping, is characterized by problem evasion and thoughts such as "wishing problems would go away or be over with" and unhealthy behaviors like over-eating, and excessive alcohol, drug and tobacco use [25].

Associations were also found between EFD and SBP. We found a negative correlation between emotion-focused disengagement and systolic blood pressure in women. This finding suggests that women that use emotion-focused engagement styles will have decreased SBP. Conversely, the Malan et al. study of men $(n=109)$ and women $(n=127)$, showed that cardiovascular effects of ineffective coping include increased diastolic blood pressure (DBP) during disengagement coping and increased systolic blood pressure (SBP) during engagement coping [21]. In other words, the ways in which an individual copes with stressful life events, does impact cardiovascular processes.

Although there were no strong correlations between PFE, SBP, or DBP in this study, men scored higher on PFE (15.39 \pm 2.66$)$ compared to women $(14.93 \pm 2.61)$. On the other hand, there was a significant correlation between SBP and PFD $(r=.065, \mathrm{p}<$ 
.01) among African American women. Problem-focused engagement (PFE) is the combination of cognitive restructuring and problem solving, and "I worked on solving the problems in the situation" is an example of problem-focused engagement, according to Tobin [43]. Krieger and Sidney [65] found that African American women who used PFE had $4 \mathrm{mmHg}$ higher SBPs compared to African American men and white men and women. 


\section{LIST OF REFERENCES}

1. Artinian, N., Washington, O., Flack, J., Hockman, E., \& Jen, K., Depression, stress, and blood pressure in urban African-American women. Progress in Cardiovascular Nursing, 2006. 21(2): p. 68-75.

2. Clark, R., Subjective stress and coping resources interact to predict blood pressure reactivity in black college students. Journal of Black Psychology, 2003. 29(4): p. 445-462.

3. Fernander, A., Duran, R., Saab, P., \& Schneiderman, N., John Henry active coping, education, and blood pressure among urban blacks. Journal of the National Medical Association, 2004. 96(2): p. 246-255.

4. Peters, R., Racism and hypertension among African Americans. West Journal of Nursing Research, 2004. 26(6): p. 612-631.

5. Wyatt, S., Akylbekova, E., Wofford, M., Coady, S., Walker, E., Andrew, M., et al., Prevalence, awareness, treatment, and control of hypertension in the Jackson Heart Study. Hypertension, 2008. 51: p. 650-656.

6. $\quad$ Peters, R., The relationship of racism, chronic stress emotions, and blood pressure. Journal of Nursing Scholarship, 2006. 38(3): p. 234-240.

7. Stein, J. \& Nyamathi, A., Gender differences in relationships among stress, coping, and health risk behaviors in impoverished, minority populations. Personality and Individual Differences, 1999. 26: p. 141-157.

8. Utsey, S., Bolden, M., Lanier, Y., \& Williams, O., III, Examining the role of culture-specific coping as a predictor of resilient outcomes in African Americans from high-risk urban communities. Journal of Black Psychology, 2007. 33(1): p. 75-93.

9. Wang, X., Trivedi, R., Treiber, F., \& Snieder, H., Genetic and environmental influences on anger expression, John Henryism, and stressful life events: The Georgia Cardiovascular Twin Study. Psychosomatic Medicine, 2005. 67(1): p. 16-23.

10. Warren-Findlow, J. \& Issel, L., Stress and coping in African American women with chronic heart disease: A cultural cognitive coping model. Journal of Transcultural Nursing, 2010. 21(1): p. 45-54.

11. Utsey, S., Ponterotto, J., Reynolds, A., \& Cancelli, A., Racial discrimination, coping, life satisfaction, and self-esteem among African Americans. Journal of Counseling \& Development, 2000. 78: p. 72-80.

12. Bennett, G., Merritt, M., Sollers, J., III, Edwards, C., Whitfield, K., Brandon, D., et al., Stress, coping, and health outcomes among African-Americans: A review of the John Henryism hypothesis. Psychology \& Health, 2004. 19(3): p. 369-383.

13. Dressler, W., Bindon, J., \& Neggers, Y., John Henryism, gender, and arterial blood pressure in an African American community. Psychosomatic Medicine, 1998. 60(5): p. 620-624.

14. Harburg, E., Gleiberman, L., Russell, M., \& Cooper, L., Anger-coping styles and blood pressure in black and white males, Psychosomatic Medicine, 1991. 53: p. 153-164. 
15. Watson, J., Logan, H., \& Tomar, S., The influence of active coping and perceived stress on health disparities in a multi-ethnic low income sample. BMC Public Health, 2008. 8(41): p. 1-9.

16. Matthews, K., Katholi, C., McCreath, H., Whooley, M., Williams, D., Zhu, S., et al., Blood pressure reactivity to psychological stress predicts hypertension in The CARDIA Study. Circulation, 2004. 110(1): p. 74-78.

17. Gentry, W., Chesney, A., Gary, H., Hall, R., \& Harburg, E., Habitual angercoping styles: I. Effect on mean blood pressure and risk for essential hypertension. Psychosomatic Medicine, 1982. 44(2): p. 195-202.

18. Addison, C., Campbell-Jenkns, B., Sarpong, D., Kibler, J., Singh, M., Dubbert, P., et al., Psychometric evaluation of Coping Strategies Inventory Short-Form (CSI$S F)$ in The Jackson Heart Study cohort. International Journal of Environmental Research and Public Health, 2007. 4(4): p. 289-295.

19. Folkman, S. \& Lazarus, R., An analysis of coping in a middle-aged community sample. Journal of Health and Social Behavior, 1980. 21(3): p. 219-239.

20. Taylor, H., Establishing a foundation for cardiovascular disease research in an African-American community--The Jackson Heart Study. Ethnicity \& Disease, 2003. 13: p. 411-413.

21. Malan, L., Schutte, A., Malan, N., Wissing, M., Vorster, H., Steyn, H., et al., Coping mechanisms, perception of health and cardiovascular dysfunction in Africans. International Journal of Psychophysiology, 2006. 61(2): p. 158-166.

22. Lazarus, R., Coping theory and research: Past, present, and future. Psychosomatic Medicine, 1993. 55: p. 234-247.

23. Folkman, S., Lazarus, R., Gruen, R., \& DeLongis, A., Appraisal, coping, health status, and psychological symptoms. Journal of Personality and Social Psychology, 1986. 50(3): p. 571-579.

24. Folkman, S., Positive psychological states and coping with severe stress. Social Science \& Medicine, 1997. 45(8): p. 1207-1221.

25. Folkman, S., Lazarus, R., Dunkel-Schetter, C., DeLongis, A., \& Gruen, R., Dynamics of a stressful encounter: Cognitive appraisal, coping, and encounter outcomes. Journal of Personality and Social Psychology, 1986. 50(5): p. 9921003.

26. Samuel-Hodge, C., Watkins, D., Rowell, K., \& Hooten, E., Coping styles, well being, and self-care behaviors among African Americans with type 2 diabetes. The Diabetes Educator, 2008. 34(3): p. 501-510.

27. Lazarus, R. \& Folkman, S., Stress, appraisal and coping. 1984(b), New York: Springer.

28. Earp, J. \& Ennett, S., Conceptual models for health education research and practice. Health Education Research Theory \& Practice, 1991. 6(2): p. 163-171.

29. Malan, L., Schutte, A.E., Malan, N.T., Wissing, M.P., Vorster, H.H., Steyn, H.S., et al., Coping mechanisms, perception of health and cardiovascular dysfunction in Africans. International Journal of Psychophysiological, 2006. 61(2): p. 158166.

30. Taber, C., Taber's cyclopedic medical dictionary, C. Thomas, Editor. 1997, Philadelphia: F.A. Davis. 
31. Dressler, W., The social and cultural context of coping: Action, gender, and symptoms in a southern black community. Social Science \& Medicine, 1985. 21: p. 499-506.

32. Whitfield, K., Jonassaint, C., Brandon, D., Stanton, M., Sims, R., Bennett, G., et al., Does coping mediate the relationship between personality and cardiovascular health in African Americans. Journal of National Medical Association, 2010. 102(2): p. 95-100.

33. Baron, R. \& Kenny, D., The moderator-mediator variable distinction in social psychological research: Conceptual, strategic, and statistical considerations. Journal of Personality and Social Psychology, 1986. 51(6): p. 1173-1182.

34. Russell, M., Cooper, M.L., Frone, M.R., \& Pierce, R.S., A longitudinal study of stress, alcohol, and blood pressure in community-based samples of blacks and non-blacks. Alcohol Research \& Health, 1999. 23(4): p. 299-306.

35. Bennett, J., Mediator and moderator variables in nursing research: Conceptual and statistical differences. Research in Nursing \& Health, 2000. 23: p. 415-420.

36. Doolan, D. \& Froelicher, E., Using an existing data set to answer new research questions: A methodological review. Research and Theory for Nursing Practice, 2009. 23(3): p. 203-215.

37. Smith, M. \& Dust, M., An exploration of the influence of dispositional traits and appraisal on coping strategies in African American college students. Journal of Personality, 2006. 74(1): p. 146-174.

38. Trentini, M., Silva, S., Valle, M., \& Hammerschmidt, K., Coping with adverse and favorable situations for older people in chronic health conditions. Latin American Journal of Nursing, 2005. 13(1): p. 1-9.

39. Levine, J., Warrenburg, S., Kerns, R., \& Schwartz, G., The role of denial in recovery from coronary heart disease. Psychosomatic Medicine, 1987. 49: p. 109117.

40. Suls, J. \& Fletcher, B., The relative efficacy of avoidant and non-avoidant coping strategies: A meta-analysis. Health Psychology, 1985. 4: p. 249-288.

41. Malan, L., Schutte, A.E., Malan, N.T., Wissing, M.P., Vorster, H.H., Steyn, H.S., et al., Specific coping strategies of Africans during urbanization: Comparing cardiovascular responses and perception of health data. Biological Psychology, 2005. 72: p. 305-310.

42. Dekker, J. \& Ormel J., Depression and coping. European Journal of Psychiatry, 1999. 13: p. 183-189.

43. Tobin, D., Holroyd, K., Reynolds, R., \& Wigal, J., The hierarchical factor structure of the coping strategies inventory. Cognitive Therapy and Research, 1989. 13(4): p. 343-361.

44. Gridler, S., Turner, J., Sherwood, A., \& Light, K., Gender differences in blood pressure control during a variety of behavioral stressors. Psychosomatic Medicine, 1990. 52: p. 571-591.

45. Utsey, S., Brown, C., \& Bolden, M., Testing the structural invariance of the Africultural Coping Systems Inventory across three samples of African descent populations. Educational and Psychological Measurement, 2004. 64: p. 185-195. 
46. James, S., Harnett, S., \& Kalsbeek, W., John Henryism and blood pressure differences among black men. Journal of Behavioral Medicine, 1983. 6: p. 259278.

47. James, S., LaCroix, A., Kleinbaum, D., \& Strogatz, D., John Henryism and blood pressure differences among black men: II. The role of occupational stressors. Journal of Behavioral Medicine, 1984. 7: p. 259-275.

48. James, S., Strogatz, D., Wing, S., \& Ramsey, D., Socioeconomic status, John Henyrism, and hypertension in blacks and whites. American Journal of Epidemiology, 1987. 126: p. 644-673.

49. Thomas, A.J., Witherspoon, K.M., \& Speight, S.L., Gendered racism, psychological distress, and coping styles of African American women. Cultural Diversity and Ethnic Minority Psychology, 2008. 14(4): p. 307-314.

50. Steffen, P.R., Hinderliter, A.L., Blumenthal, J.A., \& Sherwood, A., Religious coping, ethnicity, and ambulatory blood pressure. Psychosomatic Medicine, 2001. 63(4): p. 523-530.

51. DeCoster, V.A. \& Cummings, S., Coping with type 2 diabetes: Do race and gender matter? Social Work in Health Care, 2004. 40(2): p. 37-53.

52. Hahn, W.K., Brooks, J.A., \& Hartsough, D.M., Self-disclosure and coping styles in men with cardiovascular reactivity. Research in Nursing \& Health, 1993. 16(4): p. 275-282.

53. Lindquist, T., Beilin, L., \& Knuiman, M., Influence of lifestyle, coping, and job stress on blood pressure in men and women. Hypertension, 1997. 29(1): p. 1-7.

54. McGee, Z., Davis, B., Brisbane, T., Collins, N., Nuriddin, T., Irving, S., et al., Urban stress and mental health among African-American youth: Assessing the link between exposure to violence, problem behavior, and coping strategies. Journal of Cultural Diversity, 2001. 8(3): p. 94-104.

55. Eaton, R. \& Bradley, G., The role of gender and negative affectivity in stressor appraisal and coping selection. International Journal of Stress Management, 2008. 15(1): p. 94-115.

56. Nyamathi A., Stein, J., \& Swanson, J., Personal, cognitive, behavioral, and demographic predictors of HIV testing and STDs in homeless women. Journal of Behavioral Medicine, 2000. 23(2): p. 123-147.

57. Saab, P., Llabre, M., Schneiderman, N., Hurwitz, B., McDonald, P., Evans, J., et al., Influence of ethnicity and gender on cardiovascular responses to active coping and inhibitory-passive coping challenges. Psychosomatic Medicine, 1997. 59(4): p. 434-446.

58. Strickland, O., Giger, J., Nelson, M., \& Davis, C., The relationships among stress, coping, social support, and weight class in premenopausal African American women at risk for coronary heart disease. Journal of Cardiovascular Nursing, 2007. 22(4): p. 272-278.

59. Folkman, S. \& Lazarus, R., Coping as a mediator of emotion. Journal of Personality and Social Psychology, 1988. 54(3): p. 466-475.

60. Armstead, C., Lawler, K., Gordon, G., Cross, J., \& Gibbons, J., Relationship of racial stressors to blood pressure responses and anger expression in black college students. Health Psychology, 1989. 8: p. 541-556. 
61. Johnson, E., Schork, N., \& Spielberger, C., Emotional and familial determinants of elevated blood pressure in black and white adolescent females. Journal of Psychosomatic Medicine, 1987. 31: p. 731-741.

62. Harburg, E., Blakelock, E., \& Roper, P., Resentful and reflective coping with arbitrary authority and blood pressure. Psychosomatic Medicine, 1979. 41: p. 189-202.

63. Johnson, E., Cardiovascular reactivity, emotional factors, and home blood pressures in black males with and without parental history of hypertension. Psychosomatic Medicine, 1989. 51: p. 390-403.

64. Kroh, V., Trevisan, M., Jossa, F., Bland, S., Jalowiec, A., Celentano, E., et al., Coping and blood pressure. Journal of Human Hypertension, 1992. 6(1): p. 6570.

65. Krieger, N. \& Sidney, S., Racial discrimination and blood pressure: The CARDIA Study of young black and white adults. American Journal of Public Health, 1996. 86(10): p. 1370-1377.

66. Malan, L., Malan, N., Wissing, M., \& Seedat, Y., Coping with urbanization: A cardiometabolic risk?: The THUSA Study. Biological Psychology, 2008. 79(3): p. 323-328.

67. Light, K.C., Turner, J.R., Hinderliter, A.L., Sherwood, A., Job status and higheffort coping influence work blood pressure in women and blacks. Hypertension, 1995. 25(4): p. 554-559.

68. Wyatt, S., Akylbekova, E., Wofford, M., Coady, S., Walker, E., Andrew, M., et al., Prevalence, awareness, treatment, and control of hypertension in The Jackson Heart Study. Hypertension, 2008. 51: p. 650-656.

69. Jackson Heart Study Investigators, Protocol and manuals of operation, in Manual 2: Cohort procedures, The Jackson Heart Study, Editor. 2001, Jackson, MS: Jackson Heart Study Coordinating Center.

70. Jackson Heart Study Investigators, General description and study management visit 1, in Manual 1, The Jackson Heart Study, Editor. 2003, Jackson, MS:

Jackson Heart Study Coordinating Center.

71. Jackson Heart Study Investigators, Protocol and manuals of operation: Cohort procedures, in Manual 2, The Jackson Heart Study, Editor. 2001, Jackson, MS: Jackson Heart Study Coordinating Center.

72. Taylor, H., Wilson, J., Jones, D., Sarpong, D., Srinivasan, A., Garrison, R., et al., Towards resolution of cardiovascular health disparities in African Americans: Design and methods of The Jackson Heart Study. Ethnicity \& Disease, 2005. 15: p. 6-17.

73. Chobabian, A., Bakris, G., Black, H., Cushman, W., Green, L., Izzo, J., Jr., et al., The seventh report of the Joint National Committee on Prevention, Detection, Evaluation, and Treatment of High Blood Pressure. Journal of the American Medical Association, 2003. 289: p. 2560-2571.

74. Taylor, H., Wilson, J., Jones, D., Sarpong, D., Srinivasan, A., Garrison, R., et al. Towards resolution of cardiovascular health disparities in African Americans: Design and methods of The Jackson Heart Study. Ethnicity \& Disease, 2005. 15: p. 6-17. 
75. Jackson Heart Study Investigators, The Jackson Heart Study analysis manual, Version 4, The Jackson Heart Study, Editor. 2007, Jackson, MS: Jackson Heart Study Coordinating Center.

76. Polit, D. \& Beck, C., Nursing research: Principles and methods. 7th ed. 2004, Philadelphia: Lippincott Williams \& Wilkins.

77. Statistical Package for the Social Sciences, I., Predictive Analytical Software (PAWS), Version 18.0, Chicago, IL:IBM. 


\section{APPENDIX A. INSTITUTIONAL REVIEW BOARD APPROVAL LETTER}

\begin{tabular}{lr}
\hline THE UNIVERSITY OF TENNESSEE \\
Health Science Center \\
\hline \\
Institutional Review Board \\
& 910 Madison Avenue, Suite 600 \\
Memphis, TN 38163 \\
Tel: (901) 448-4824
\end{tabular}

April 5, 2010

Sandra Henley Williams

College of Nursing

Department of Nursing

Re: 10-00775-XM: Coping Style and Blood Pressure in African Americans: The Jackson Heart Study

Dear Ms. Williams,

The IRB has received your written acceptance of and/or response dated March 29, 2010 to the provisos outlined in our correspondence of March 16, 2010 concerning the application for the above referenced project.

The Administrative Section of the IRB determined your application to be consistent with the guidelines for exempt review under 45CFR46.102(f) in that it does not involve human subjects as defined therein. Informed consent is waived in accord with 45CFR46.116(d).

Therefore your application has been determined to comply with proper consideration for the rights and welfare of human subjects and the regulatory requirements for the protection of human subjects. This letter constitutes full approval of your application for the above referenced study.

This study may not be initiated until you receive approval from the institution(s) where the research is being conducted.

In the event that volunteers are to be recruited using solicitation materials, such as brochures, posters, webbased advertisements, etc., these materials must receive prior approval of the IRB.

Any alterations (revisions) in the protocol must be promptly submitted to and approved by the UTHSC Institutional Review Board prior to implementation of these revisions. You have individual responsibility for reporting to the Board in the event of unanticipated or serious adverse events and subject deaths.

Sincerely,

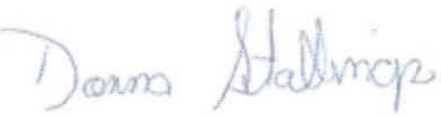

Signature applied by Donna L Stallings on 04/05/2010 12:55:34 PM CDT

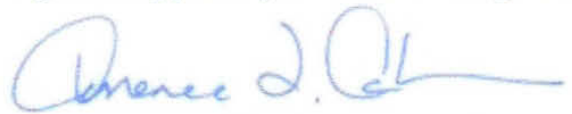

Signature applied by Terrence F Ackerman on 04/05/2010 12:59:15 PM CDT

Donna Stallings, CIM

IRB Analyst

UTHSC IRB
Terrence F. Ackerman, Ph.D.

Chairman

UTHSC IRB 


\section{APPENDIX B. JHS MANUSCRIPT PROPOSAL APPROVAL LETTER}

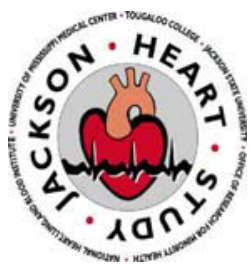

JACKSON HEART STUDY

Jackson Medical Mall, Suite 701 - 350 West Woodrow Wilson Drive

- Jackson, MS 39213 • Phone: 601-979-8700 • Fax: 601-979-8701

February 26, 2010

Sandra H. Williams, PhD Candidate

1027 St. Moritz Dr. W

Mobile, AL 36608

Dear Sandra,

The Publications and Presentations Subcommittee want to thank you for re-submitting your manuscript proposal entitled, "Coping Responses and Blood Pressure in African Americans: The Jackson Heart Study." There has been great improvement in this submission, therefore the P\&P Reviewers have voted to "accept as is" A copy of the evaluation comments is included (see attachments) for your review.

Lead authors of proposals that receive a recommendation of "accept as is" along with reviewer comments, have the option of addressing the comments before the proposal is advanced to the next step. If the Lead author plans to do so, he/she should inform the PPS Chair and Administrative Coordinator that a revised proposal is forthcoming and the expected date.

A period of 2 years is allowed for publication of the manuscript from a given proposal from the date of the availability of data. "Languishing manuscripts" (those inactive after 2 years) are eligible for recommendation by the PPS for reassignment to other interested investigators. High priority manuscripts are subject to a recommendation for reassignment when it is determined by the PPS that undue delay in the preparation of the manuscript has occurred.

We look forward to the final product.

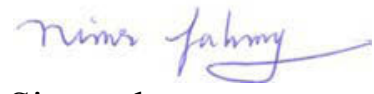

Sincerely, Nimr Fahmy, PhD 
Chair, Publications and Presentations Subcommittee

\begin{tabular}{|l|l|}
\hline Date of Submission & $02 / 2009$ \\
\hline Reconsider after revisions & $02 / 25 / 2009$ \\
\hline Re-submitted & $03 / 17 / 2009$ \\
\hline Reconsider after revisions & $03 / 25 / 2009$ \\
\hline Request for an Extension & $05 / 28 / 2009$ \\
\hline Resubmitted & $10 / 2009$ \\
\hline Accepting pending revisions & $10 / 28 / 2009$ \\
\hline Resubmitted & $02 / 16 / 2010$ \\
\hline Accept as is & $02 / 26 / 2010$ \\
\hline
\end{tabular}

Evaluator's Comments

The authors have really thought out the proposal and have provided a very sound analytic approach to answering the proposed research hypotheses/questions.

The Jackson Heart Study has unique data to explore the contributions of psychosocial stress to cardiovascular disease in African Americans. There is evidence that different coping styles are associated with positive and negative health outcomes, but limited evidence of how different coping styles may affect health, and specifically, high blood pressure, in African Americans. This study will utilize the JHS data to describe the prevalence of several different coping styles and their relationship to clinic blood pressure, prevalence of hypertension, and control of hypertension. The JHS also contributes to the training of future health scientists, and this study is a dissertation project. 
APPENDIX C. COPING STRATEGIES INVENTORY SHORT-FORM

ID NUMBER:

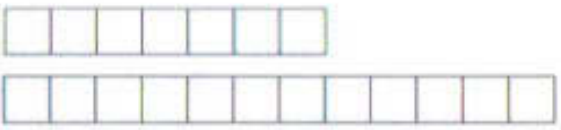

CONTACT YEAR:

FORM CODE: CSI

LAST NAME:

INSTRUCTIONS: People often experience events that are unpleasant or stressful. We are interested in how you TYPICALLY HANDLE OR COPE with stress. The items below represent thoughts or behaviors that people use to cope with stress. Circle a number next to each item to show how often you cope with stress in that way. If a number is circled incorrectly, mark through it with an " $\mathrm{X}$ " and circle the correct response.

\begin{tabular}{|l|l|l|l|l|}
\hline Never & Seldom & $\begin{array}{c}\text { Some- } \\
\text { Times }\end{array}$ & Often & $\begin{array}{l}\text { Almost } \\
\text { Always }\end{array}$ \\
\hline
\end{tabular}

1. I make a plan of action and follow it.... . .1

2

3

4

2. I look for the silver lining or try to look on the bright side of things...... 1

3. I try to spend time alone 


\begin{tabular}{|l|l|l|l|l} 
Never & Seldom & $\begin{array}{c}\text { Some- } \\
\text { Times }\end{array}$ & Often & $\begin{array}{l}\text { Almost } \\
\text { Always }\end{array}$ \\
\hline
\end{tabular}

4. I hope the problem will take care of itself.

2

3

5

5. I try to let my emotions out.

2

3

5

6. I try to talk about it with a friend or family.

2

3

7. I try to put the problem out of my mind

2

3

5

8. I tackle the problem head-on

2

5

9. I step back from the situation and try

to put things into perspective.

2

4

5

10. I tend to blame myself 


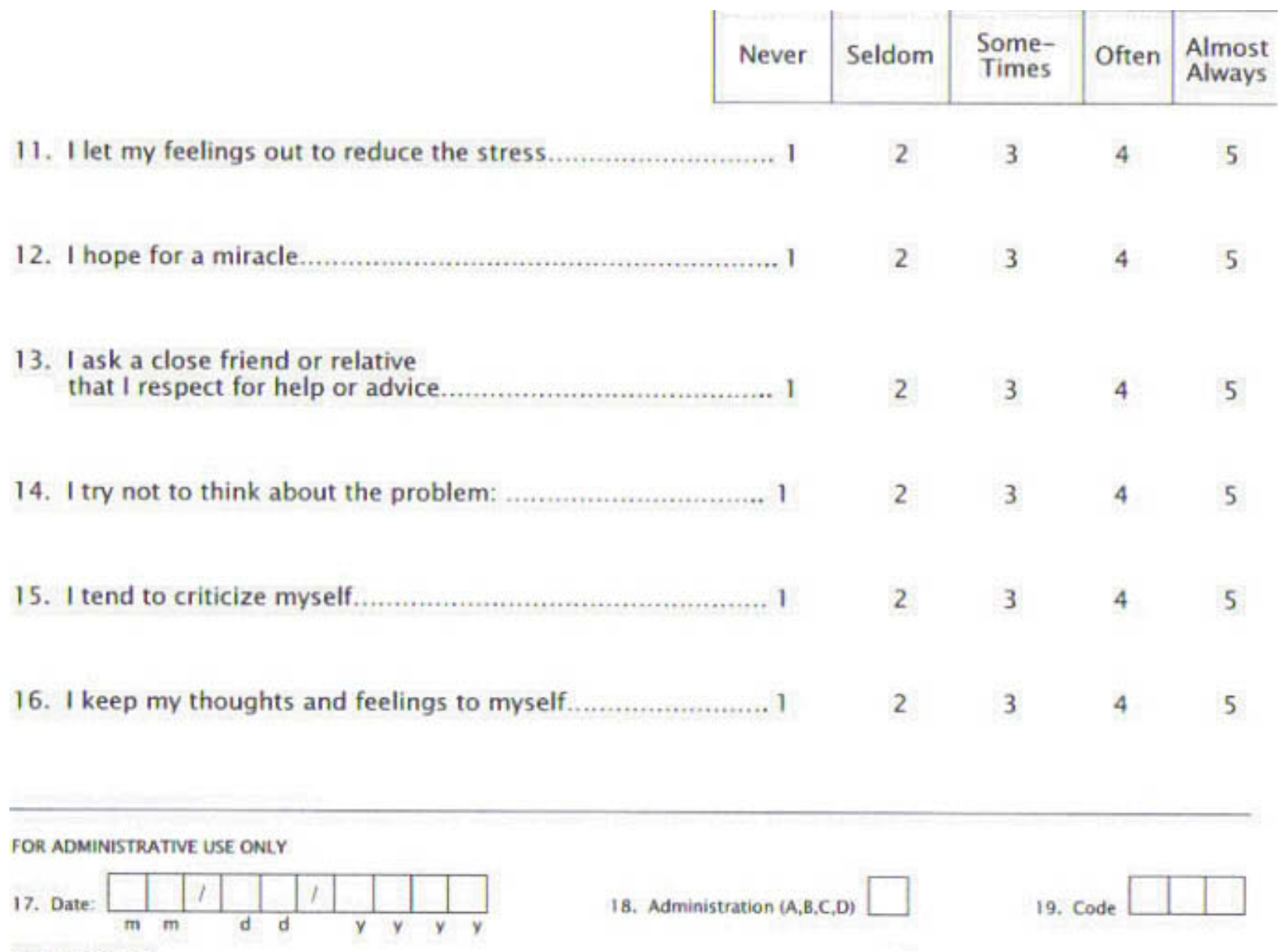


APPENDIX D. TOBACCO USE FORM

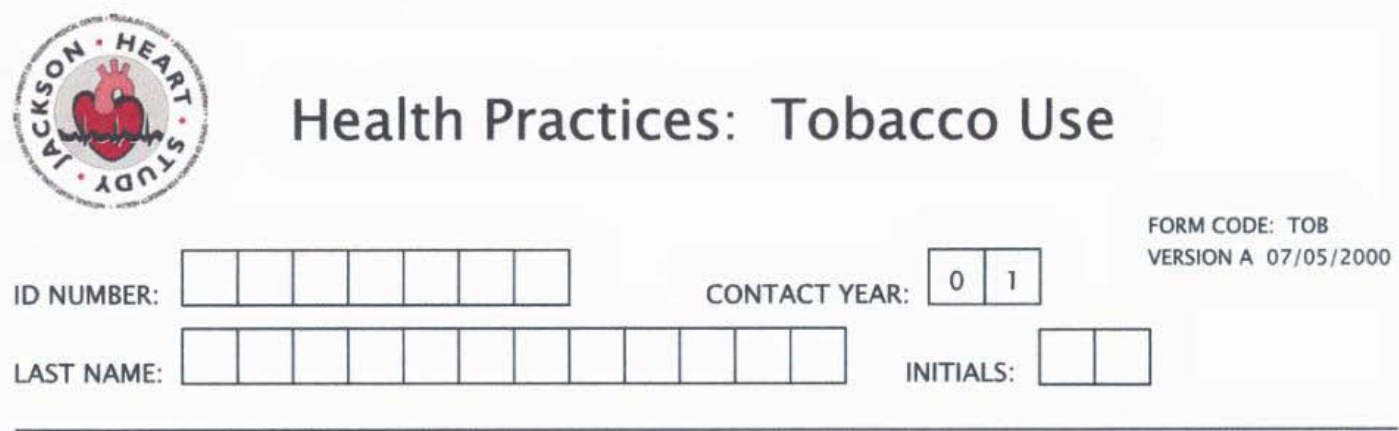

"Now I have a series of questions about your health habits. These first questions will be about tobacco use."

1. Have you smoked at least 400 cigarettes in your lifetime? ICODE "NO" IF LESS THAN 400 CIGARETTES, THAT IS, 20 PACKS OR 2 CARTONS IN A LIFETIME] .......................................... Yes

Go to Item 14

2. How old were you when you first started to smoke cigarettes regularly, that is, every day? [ENTER "00" IF NEVER SMOKED REGULARLY]........ If " 00 ", go to Item 12

3. Do you now smoke cigarettes? ... Yes $\mathrm{Y}$ Go to Item 5

No

$\mathrm{N}$

4. How long has it been since you last smoked cigarettes? $4 a$. [CALCULATE \# OF MONTHS AND YEARS BASED ON PARTICIPANT RESPONSE]

$4 b$.

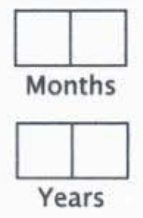


IF PARTICIPANT HAS SMOKED CICARETTES WITHIN THE PAST 3 MONTHS, SAY: "Please answer the next few questions with regard to your current or recent cigarette smoking practices."

IF PARTICIPANT HAS NOT SMOKED CIGARETTES WITHIN THE PAST 3 MONTHS, SAY: "Please answer she next few quesbions with regard to your usual cigarette smoking practices before you quit."

5. How many cigarettes do (did) you smoke per day?

[ENTER EXACT NUMBER. CODE $1 / 2$ CIGARETTE

PER DAY AS 01, ANYTHINC LESS AS 00.]

Cigarettes

5. Do (did) you smoke more frequently during the first few hours after awakening than during the rest of the day?

Yes

Y

No

$\mathrm{N}$

7. How soon after you wake (woke) up do (did) you smoke your first cigarette? Would you say within the first 5 minutes. the first 30 minutes, the first hour, or more than an hour after awakening?

3. Of all the cigarettes you smoke (smoked) during the day, which one would you hate (have hated) to give up most? [ANSWER MUST BE STATED AS A TIME; PLACE/SITUATION. IF PARTICIPANT STATES 'IN THE MORNINC", "WHEN I GET UP" "WITH MY COFFEE" OR A SIMILAR RESPONSE, CLARIFY.J.

7. Do (did) you find it difficuit to refrain from smoking in places where it is forbidden, for example, in church, the library, cinema, etc?

10. Do (did) you smoke if you are (were) so ill that you are (were) in bed most of the day?

11. On the average, for the entire time you have smoked, how many cigarettes did you usually smoke per day? IENTER EXACT NUMBER. CODE $Y$ CICARETTE PER DAY AS 01, ANYTHINC LESS AS O0 
12. Since you began smoking, for how many years were you off cigarettes?

13. How deeply do (did) you inhale the cigarette smokenot at all, slightly, moderately, or deeply?

$\begin{array}{ll}\text { Not at all } & \text { N } \\ \text { Slightly } & \text { S } \\ \text { Moderately } & \text { M } \\ \text { Deeply } & \text { D }\end{array}$

14. Have you ever used any other tobacco products regularly, that is cigars or cigarillos, pipes, chewing tobacco, or snuff/dip?

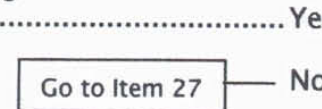

15. What is the total number of years you have smoked cigars or cigarillos regularly?

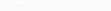

..................

If " 00 ", go to Item 18

16. Over the course of the entire time you smoked cigars or cigarillos, how many cigars or cigarillos per week have you typically smoked?

\section{Cigars or}

Cigarillos

17. Do you currently smoke cigars or cigarillos?

18. What is the total number of years you have smoked a pipe regularly?

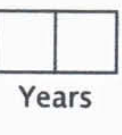

If " 00 ", go to Item 21

19. Over the course of the entire time you have smoked a pipe, how many pipefuls per week have you typically smoked?

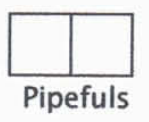


20. Do you currently smoke a pipe?.

21. What is the total number of years you have used chewing tobacco such as Redman, Beechnut or Levi Garret, regularly?

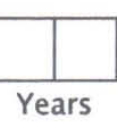

If " 00 ", go to Item 24

22. Over the course of the entire time you have used chewing tobacco, how many pouches per week have you typically chewed?

[A STANDARD POUCH CONTAINS 3 OUNCES]

23. Do you currently use chewing tobacco?

24. What is the total number of years you have used snuff or dip, such as Skoal, Bandits or Copenhagen, regularly?

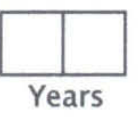

If " 00 ", go to Item 27

25. Over the course of the entire time you have used dip or snuff, how many cans per week have you typically used? [A STANDARD CAN CONTAINS 1.2 OUNCES]...

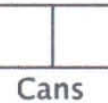

26. Do you currently use dip or snuff? Yes

27. [ASK EVERYONE] During the past year, about how many hours per week, on the average, were you in close contact with people where they were smoking? For example, at work, your home, in a car, or other close quarters?

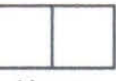

Hours 
ADMINISTRATIVE INFORMATION

28. Date of data collection:

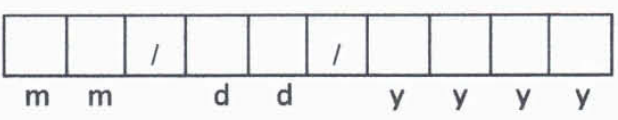

29. Code number of person completing this form: 


\section{APPENDIX E. ALCOHOL AND DRUG USE FORM}

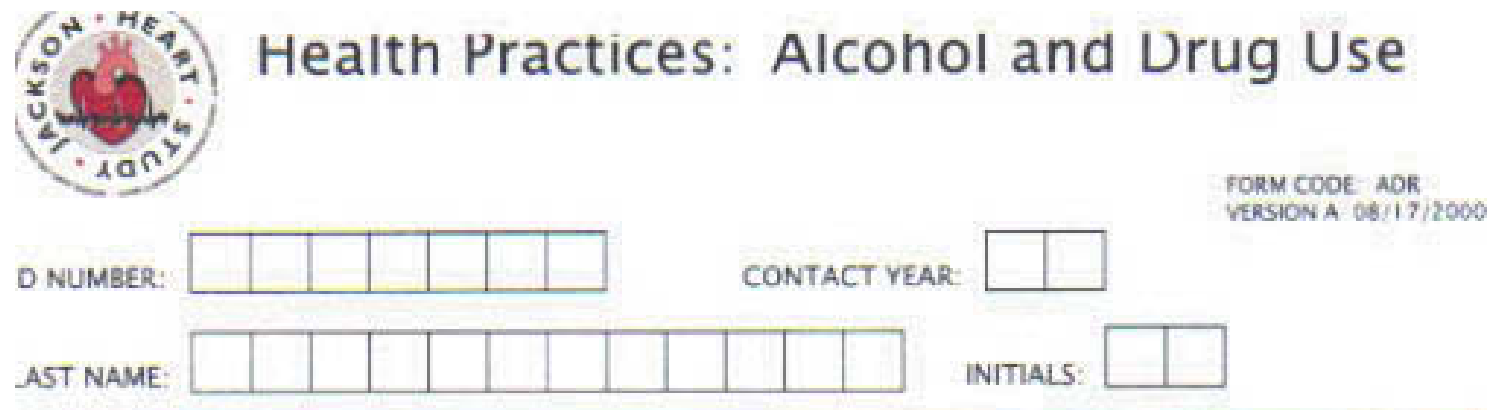

INSTRUCTIONS: This form should be completed during the participant's clinic visit, ID Number, Contact Year, and Name must be entered above. Whenever numencal responses are required, enter the number so that the last digit appears in the rightmost box. Inter leading zerces where necessary to fill all boxes. If a number is entered incorrectiy, mark through the incorrect entry with an ' $\mathrm{X}$ '. Code the correct entry clearly above the incorrect entry. For "multiple choice" and 'yes/ no' type questions. circle the letter corresoonding to the most appropriate resoonse. If a letter is circled incorrectly, mark through it with an ' $x$ ' and circle the correct response.

These next questions are about drinking alcoholic beverages. Alcoholic beverages include beer, ale, wine. Nine coolers, liquor such as whiskey, gin, rum, or vodka, and cocktails and mixed drinks containing liquor." SHOW RESPONSE CARD OF BEVERACES] "Here are some kinds of alcoholic beverages people drink."

1. Have you ever consumed alcoholic beverages? ...... Yes

\begin{tabular}{|c|c|c|c|}
\hline Co to item 6 & No & \multicolumn{2}{|l|}{$\mathrm{N}$} \\
\hline & more than one year ago & S & Co to item \\
\hline
\end{tabular}

2. During the past 12 months, on the average, how many days per week, month, or year did you drink any alcoholic beverage?

2a. Number of days:

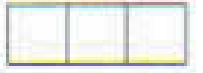

2b. Per [UNIT OF TIME]:

$\begin{array}{ll}\text { Week } & \text { W } \\ \text { Month } & \text { M } \\ \text { Year } & \text { Y }\end{array}$

3. On the average, on the days that you drank alcohol,

how many drinks did you have a day? (By a drink.

I mean a 12 -ounce beer, a four-ounce glass of wine,

or an ounce of liquor.)

[SHOW RESPONSE CARD OF SERVINC SIZE]

Specify number of drinks:

[ENTER * $88^{*}$ IF DON'T KNOW] 
4. When you drink, do you usually drink beer, wine,

of liquor?

Beer B

Wine $\quad$ w

Liquor $\quad 1$

No preference

or can't say

N

5. Was there ever a time or times in your life when you

drank 5 or more drinks of any kind of alcoholic

beverage almost every day?

"The next few questions are about your experiences with drugs."

6. Have you ever used crack or cocaine in any form? Yes

[SHOW RESPONSE CARD OF

CRACK/COCAINE FORMS:

Co to item :

7. About how many times in your lifetime have you used crack or cocaine (in any form)? 1 or 2 times

A

3-10 times

B

11-99 times

C

100 or more times

D

8. Have you ever used any other kinds of drugs, including

marijuana, heroine, or others?

[SHOW RESPONSE CARD OF OTHER DRUC FORMS]

\section{ADMINISTRATIVE INFORMATION}

9. Date of data collection

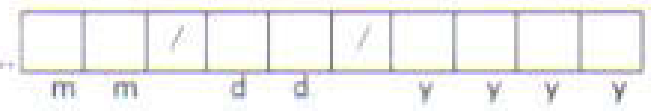

10. Method of data collection

11. Code number of person completing this form: 


\section{VITA}

Sandra Henley Williams was born in Mobile, AL, in 1960. She attended Bishop State Community College, where she graduated with an Associate degree in General Studies with honors and was awarded a Certificate in Practical Nursing; she was inducted into the Phi Theta Kappa National Honor Society in 1995. While working as a licensed practical nurse (LPN) on an obstetrical and gynecological (OB/GYN) unit, she enrolled at the University of Mobile, where she graduated with a Bachelor of Science in Nursing in 1999 and a Master of Science in Nursing with honors in 2002. She was inducted into the Omicron Theta Chapter of Sigma Theta Tau International Honor Society of Nursing and the Alpha Theta Chi Collegiate Honor Society in 2002. In 2005, she joined the faculty at the University of South Alabama, College of Nursing. Her duties as an instructor included teaching and academic advising as well as course coordinator for Foundations of Professional Nursing. Responsibilities included coordinating clinical experiences, developing course exams, course schedules, and clinical rotations at local healthcare facilities. She served as Clinical Lab Coordinator, for which she maintained inventory lists of supplies as well as development of item lists for purchases. In 2006, she was accepted into the Doctor of Philosophy of Science in Nursing Program at the University of Tennessee Health Science Center (UTHSC). While enrolled at UTHSC, she was a recipient of the National Association of Student Nurses Promise of Nursing Fellowship in 2007 and became a NIH/NINR Summer Genetics Fellow in 2008.

The University of Tennessee Health Science Center, Memphis, TN, awarded Sandra Henley Williams a Doctor of Philosophy in nursing degree in December 2010. Her dissertation research concentrated on the relationship between coping style and blood pressure in African Americans. She plans to further her program of research while completing postdoctoral training in cardiovascular genomics at the University of Pittsburgh. 